\title{
Consumer Switching Costs in Mobile Telecommunications
}

\author{
by
}

Laura Sonley, BA (Hons) Econ.

\author{
A thesis submitted to the \\ Faculty of Graduate Studies and Research \\ in partial fulfillment of \\ the requirements for the degree of
}

Masters of Arts in Economics

Department of Economics

Carleton University

Ottawa, Ontario, Canada

C Copyright 2014, Laura Sonley 


\begin{abstract}
In this Thesis I investigate the effectiveness of promoting competition through a reduction in consumer switching costs in the mobile telecommunications market. I modify an analytical model by Shi et al. (2006) to determine whether a reduction in switching costs can stimulate competition in Canada's wireless telecommunications market. More specifically, I use the example of eliminating fees for unlocking mobile phones. The model predicts that a reduction in switching costs may accelerate the gain in market share by the larger network. I also find that a decrease in switching costs decreases the fixed fee paid by subscribers to the smaller firm but increases the fixed fee charged by the larger firm. In aggregate, I find that consumer welfare and the impact of eliminating unlocking fees on total industry profits is dependent on relative market shares and the size of the remaining switching costs present in the market. Given the results of my analytical model, I survey the empirical research of switching costs in mobile telecommunications and find evidence that supported the conclusions of my model. From this evidence I provide policy recommendations for future consideration.
\end{abstract}




\section{Acknowledgements}

I would like to express my deepest gratitude to my supervisor, Professor Zhiqi Chen, who has helped me through each stage of writing of this Thesis. I have learnt a great deal from him throughout this process. Without his instructive advice and useful suggestions, this Thesis could not have reached its present form. In the preparation of this Thesis, he has spent much time reading through each draft and provided me with ample help when needed. I am especially grateful for his patience. 


\section{Table Of Contents}

$\underline{\text { Abstract }}$ ii

$\underline{\text { Acknowledgements }}$ iii

Table of Contents $\quad$ iv

List of Figures $\quad$ vi

List of Tables $\quad$ vii

CHAPTER 1: Introduction 1

CHAPTER 2: Canadian Telecom Industry And Policy $\quad 5$

SECTION 2.1: Challenges ENTRANTS

SUBSECTION 2.1.1: SPECTRUM SCARCITY

SUBSECTION 2.1.2: FOREIGN OWNERSHIP RESTRICTIONS 10

SECTION 2.2: WIRELESS CODE OF CONDUCT

SECTION 2.3: CONCLUSIONS

CHAPTER 3: Theoretical Evidence $\quad 19$

SECTION 3.1 SWITCHING COST THEORY

SECTION 3.2 THE MODEL $\quad 23$

SUBSECTION 3.2.1 STAGE 2: CONSUMER SUBSCRIPTION DECISION 24

SUBSECTION 3.2.2 STAGE 1: CARRIER PRICING DECISION 29

SUBSECTION 3.2.3 EQUILIBRIUM CONDITIONS

SUBSECTION 3.2.4 EQUILIBRIUM ANALYSIS

SUBSECTION 3.2.5 CONSUMER WELFARE

SUBSECTION 3.2.5 CONCLUSIONS

Chapter 4: Empirical Evidence $\quad 43$

SECTION 4.1: Portability PERIOd AND FEe

SUBSECTION 4.1.1: LESSONS FROM WNP IN EUROPE 46

SECTION 4.2: NETWORK EFFECTS 48

SUBSECTION 4.2.1: EVIDENCE FROM THE GERMAN TELECOM MARKET 48

SUBSECTION 4.2.2: EVIDENCE FROM JAPAN'S TELECOM MARKET

SUBSECTION 4.2.3: EVIDENCE FROM UK TELECOM MARKET

SUBSECTION 4.2.4: EVIDENCE FROM THE SWEDISH TELECOM MARKET

SECTION 4.3 HIDDEN COSTS

SUBSECTION 4.3.1: EVIDENCE FROM WNP IN EUROPE 
SUBSECTION 4.4.2: EVIDENCE FROM WNP IN THE US

SECTION 4.4 SIZE OF REMAINING SWITCHING COSTS

SUBSECTION 4.4.1: LESSONS FROM WNP IN THE US

SUBSECTION 4.4.2: LESSONS FROM WNP IN JAPAN

SUBSECTION 4.4.3: LESSONS FROM WNP IN KOREA

SECTION 4.5 INCENTIVIZING HANDSET MANUFACTURERS

Chapter 5: Conclusions and Policy Recommendations

References 


\section{List of Figures}

Figure 4.2.1 Industry growth with and without network effects

Figure 4.2.3 Development of on- and off-net call volumes 68

Figure 4.3 Direct costs of WNP using ONS or IN technology 69 


\section{List of Tables}

Table 4.1.1 Evolution of WNP implementation in the European 


\section{CHAPTER 1:}

\section{Introduction}

Currently, three incumbent service providers oligopolize the Canadian mobile communications market, controlling $90 \%$ of the market between them (CMCRP, 2013) ${ }^{1}$. In Canada, the number of mobile phones per capita is $20 \%$ lower than in the United States. In this respect, Canada has a lower number of mobile phones per capita than Mexico, which still operates under a near-monopoly carrier. ${ }^{2}$ The proportion of people in Canada with mobile broadband is less than half that in the United States. Canada also maintains prices higher than the US and profit margins in Canada's telecommunications industry are among the highest in the OECD (Cave \& Foster, 2010). For these reasons, among others the Canadian telecommunications market has been the cause of much political deliberation in recent years.

Since the 1968 Canada's telecom regulator, The Canadian Radio-Television and Telecommunications Commission (CRTC), has implemented many policies in order to promote competition in the mobile communication market and ensure the protection of consumer choice. All the while, the incumbent mobile carriers, Bell Mobility (Bell), Telus Mobility (Telus) and Rogers Telecom (Rogers), have been adept at revising their strategies in order to sustain their market position. One common practice of the three incumbent carriers is increasing switching barriers for customers, such as restrictive

\footnotetext{
${ }^{1}$ The $90 \%$ figure refers to the market share in terms of revenues. Canadian Media Concentration Research Project (CMCRP). Platform Media Industries: Wireless Communications. Retrieved November 26, 2014, from http://www.cmcrp.org/wp-content/uploads/2014/11/Wireless-Communications-2013.xlsx. ${ }^{2}$ In 2013, the mobile penetration rate (per 100 people) is 78, 86, 96 in Canada, Mexico and the United States, respectively (Wold Bank, 2014).
} 
contracts, "locking" devices and/or locking the Subscriber Identity Module (SIM) to a particular service provider. This significantly impacts the landscape of the telecommunications market and thus, merits an investigation of the impact of switching costs on competition in wireless mobile communications.

The telecommunications market represents a significant portion of the Canadian economy. According to the CRTC (2013), the total revenues of the telecom industry were $\$ 43.9$ billion- representing 3.3 of Canada's gross domestic product in 2012. The Canadian telecommunications market is also an important piece of infrastructure. Canadian firms rely on telecom in order to compete internationally including attracting foreign investment, and positioning Canada as a global trading nation. Efficient management of Canadian telecom is critical not only to consumer welfare but also to Canadian business and foreign relations.

There have been two recent policies implemented by Industry Canada and the CRTC in their effort to promote competition in the wireless telecommunications industry. The first policy was aimed at promoting new entry into the mobile telecommunications sector. This was primarily attempted through restricting incumbent participation in spectrum auctions and limiting spectrum aggregation. For example, in 2008 during the Advanced Wireless Services (AWS) spectrum auction, the government reserved $40 \%$ of available spectrum for companies having less than $10 \%$ of the national wireless market based on revenue. In addition, spectrum caps were put in place which restrict the amount one company can obtain for the $700 \mathrm{MHz}$ auction held in 2014 (CSPR, 2014) $)^{3}$. The second policy was aimed at promoting competition between existing wireless carriers.

${ }^{3}$ Canadian Spectrum Policy Research (CSPR). Auctions. Retrieved November 26, 2014, from http://canadianspectrumpolicyresearch.org/auctions/. 
This was implemented through the Wireless Code of Conduct (2013) which seeks to reduce the cost of switching between mobile carriers through regulations surrounding unlocking devices and termination fees, among others.

This thesis tries to shed some light on the effectiveness of the latter angle. To do so I modify an analytical model by Shi et al. (2006) to determine whether a reduction in switching costs can stimulate competition in Canada's wireless telecom market. More specifically, I will examine the example of eliminating fees for unlocking mobile phones.

Additionally, I assess my results in the context of recent empirical findings regarding an elimination or reduction of switching costs in the wireless telecommunications market. The most prominent reduction in recent history is the introduction of wireless number portability (WNP), which allowed consumers to carry their phone number with them when switching between wireless carriers. I draw conclusions based on the lessons learned through the ample empirical analysis of the effects of WNP. I also take into account studies of the effects of unlocking the SIM, a policy that is much more current, and less widespread. From my model and empirical investigation I am able to generate policy recommendations for future policy intervention.

This thesis is organized as follows. In the second chapter, I will provide context on Canadian telecom industry and policy as it stands today. In chapter 3 I analyze the current economic literature and further propose a model of competition with consumer switching costs. Using the model framework I analyze equilibrium consumer fees, firm profits, firm market shares, and consumer welfare. In chapter 4 I examine the empirical 
evidence regarding switching costs in telecom services. In chapter 5 I discuss possible policy considerations for future regulation and conclude. 


\section{CHAPTER 2:}

\section{Canadian Telecom Industry and Policy}

Until recently, the CRTC has focused their efforts on assisting the introduction of a fourth facility-based carrier with a goal of disciplining the currently elevated telecom rates. The results have not been as promising as hoped thus far, with one potential entrant in bankruptcy proceedings and another having been bought out by an incumbent carrier. In response, in 2013 the CRTC took a different approach by introducing the Wireless Code of Conduct (WCC). The two overarching provisions in the WCC were to reduce consumer-switching costs and increase contract transparency. The code mandated contract provisions such as handset unlocking, restrictions on contract length and a reduction in termination fees. The model I present in chapter 3 theorizes the potential effects of a reduction in switching costs such as those contemplated in the WCC. This chapter is organized as follows. In Section 2.1 I will examine the difficulties that have arisen for new carriers attempting to enter the Canadian market. In Section 2.2 I outline the provisions of the WCC and will assess the legitimacy of regulations in subsequent chapters.

\subsection{Challenges for Entrants}

In this section I will examine two of the greatest challenges that entrant carriers have faced in achieving profitability: spectrum scarcity and foreign ownership restrictions. In doing so, I will draw on examples from the experience of four of the most 
promising new entrants into the Canadian telecom market, namely Shaw, Wind, Mobilicity and Public Mobile.

\subsubsection{Spectrum Scarcity}

With the increasing dissemination of wireless technology and increasing demand for wireless products and services, the government has been struggling to sustain the capacity of government allocated spectrum. We are not only experiencing growth due to the universality of mobile phones, but also the growth of wireless technology for emergency services and wireless television services among others. Scarcity of spectrum naturally limits on the number of competing network operators in the mobile market.

A primary concern in managing spectrum is the need to regulate spectrum use in a way that minimizes spectrum interference and ensures the availability of bands used by the public sector, such as public safety radio and spectrum for medicinal machinery (Cave \& Foster, 2010). Until recently, spectrum reform has focused on enhancing administrative tools such as licensing, technical standards and reallocation of vacated frequencies.

In 2002, Industry Canada revised the 1992 Spectrum Policy Framework to reflect the tremendous amount of change in the industry since the original policy framework was written. In this new framework, Industry Canada decided to veer from its usual practice of presenting licenses based on a comparative business review (Cave \& Foster, 2010): “...the Department has adopted a number of changes in spectrum policy and management. One specific example is the Department's adoption of the option of using auctions as a means of determining who should be selected among multiple competing 
applicants for radio licenses where there is not sufficient spectrum to meet projected demand" (Industry Canada, June 2002, p. 2). The justification for the policy change was that auctions are a faster, more transparent way of allocating spectrum, which would enable Industry Canada to promote the efficient use of spectrum, and encourage companies to deploy the most spectrum possible. Much of the redesign was intended to avoid collusion, barriers to entry and exercises of market power (CSPR, 2014).

Some believe introducing the auction design itself is only a partial solution. An auction assigns permanent ownership to the purchaser of the spectrum in question. As a result, the user who purchased it at the time may in the future not be able to use the spectrum in the most profitable and efficient way. The potential for a transfer or adjustment of ownership would be a step in the right direction toward an efficient allocation of spectrum. This is becoming increasingly important for ensuring innovation in an increasingly scarce market for frequencies.

The ability to transfer or adjust ownership is particularly applicable to the Canadian market as coupled with a spectrum shortage in Canada is the prevalence of spectrum that has been allocated by Industry Canada but is underutilized (Cave \& Foster, 2010). For example, one year after purchasing Public Mobile, Telus Mobility has dismantled Public Mobile's CDMA network, leaving this spectrum unused (Telus, 2014). There are those who believe that releasing underutilized and surplus spectrum for commercial use would generate government revenues and improve competition, leading to lower wireless prices for consumers. Additionally, it has been suggested that Canada should allow spectrum holders greater flexibility to trade and change the aggregation of 
their spectrum in secondary markets. The idea being that this will efficiently allocate spectrum to the most valued end use no matter who purchases it initially through an auction.

Flexibility in spectrum assignment has been the strategy recently adopted by the United States. The US has moved increasingly towards flexible spectrum after commissioning the FCC's Spectrum Policy Task Force in 2002 (Cave \& Foster, 2010). The Task Force Report identified the key failing of spectrum allocation in the US as being administrative rigidities preventing a more efficient allocation of spectrum. As a result, the US has since held the most spectrum auctions (72) and the most spectrum trades in the OECD while Canada lags behind having conducted a total of 7 auctions since 2009 .

There have been many other suggested solutions to circumvent spectrum scarcity. One among them is the introduction of mobile virtual network operators (MVNOs). MVNOs provide wireless services without owning the wireless network infrastructure. An MVNO would enter into an agreement with an existing mobile network to obtain access to their network on a wholesale basis and resell to consumers at an independently set rate. Examples of existing MVNOs in Canada are Koodoo (on the Telus network), Fido (on the Rogers network), and Virgin Mobile (on the Bell network). MVNOs are prevalent internationally but for an MVNO to operate in Canada they would have to be dependent entirely on regulation for access to incumbent networks.

In sum, significantly increased demand for wireless products has strained the current spectrum allocation process and has resulted in a gridlock that has artificially 
constrained supply and driven up prices of spectrum creating significant barriers for entrants in the telecommunications industry. As a result, without compelling financial backing it is hard for a new entrant to compete after incurring the significant costs paid for spectrum at auction. A potential remedy could be greater flexibility towards the trade and auction of spectrum in order to reallocate misused spectrum given the scarce climate. I will further examine the issue of spectrum scarcity in the context of recent entrants' experience with large scale spectrum purchases.

\section{The Experience of Entrants}

After the aforementioned 2008 AWS spectrum auction, new competitors namely, Wind Mobile, Public Mobile, Mobilicity and Videotron-emerged. It was anticipated that in some parts of the country there would be six facility-based carriers in competition for subscribers. Public Mobile was one of several new cell phone providers that launched in 2010. Public Mobile, a Toronto-based start-up, purchased \$52 million of spectrum reserved for entrants (Public Mobile, 2008). In October 2013, Public Mobile had approximately 280,000 subscribers (CWTA, 2014) ${ }^{4}$. However, Public Mobile announced it did not have the finances to continue to combat multiple competitors. To compete with the incumbents by carrying the high-speed LTE service, it would need a significant cash inflow to expand its network, and buy spectrum in the upcoming 700 $\mathrm{MHz}$ band.

Similarly, Mobilicity filed for creditor protection in September 2013 (Mobilicity, 2013). Mobilicity is one of the smallest players in Canada with 250,000 subscribers in its prime (CWTA, 2014). Telus has since made three failed attempts to purchase Mobilicity.

\footnotetext{
${ }^{4}$ Canadian Wireless Telecommunications Association (CWTA). Wireless Phone Subscribers in
} Canada-2014. Retrieved November 27, 2014, from http://cwta.ca/facts-figures/. 
The federal government warned the incumbent in a comment to the Globe and Mail that it would take retaliatory measures in the upcoming auction against incumbents if Telus did not abandon its bid for Mobilicity (Globe and Mail, Apr 25, 2014). This turn of events leaves Mobilicity, now in bankruptcy protection, without a desirable bidder to take over its business.

Shaw was successful in acquiring approximately 20 megahertz of reserved spectrum across its existing cable operating footprint in Western Canada and Northern Ontario (Shaw, 2008). In a press release in July 2008, Shaw stated “Our advantage is that we have an extensive network supported by 10,000 employees and multiple products already on the market." Shaw did not launch as it decided that entering the telecommunications market was too expensive. They have since attempted to sell their spectrum to incumbent carrier Rogers.

Videotron is the only new entrant that has been a disciplining force for one of the incumbents, however only on regional bases. The new entrant has been succeeding in taking significant market share from Bell in Quebec (CWTA, 2014). However, the big three still maintain over 90 per cent of subscribers in Quebec this year, with Bell holding 33\% market share (CMCRP, 2014).

\subsubsection{Foreign Ownership Restrictions}

Canada is one of only 9 OECD countries to maintain foreign ownership restrictions on telecommunication services and has one of the most restrictive policies towards foreign ownership among the developed world (Cave \& Foster, 2010). The telecommunications market has over the past decade become a global business, with carriers expanding outward to become globally competitive with companies, like Britain's 
Vodafone Group PLC, Spain's Telefonica SA or Germany's T-Mobile, all of which are multinational forces (Asimakopoulos \& Sánchez, 2012). Since 1993, the Telecommunications Act has required that 80 per cent of the voting shares of Canadian companies belong to Canadians. Their boards of directors must also be 80 percent Canadian (Industry Canada, 2010). In an industry protected from foreign pressure there is less incentive to innovate, improve upon available services and lower subscription prices for consumers.

Internationally, it is not uncommon for telecommunications markets to manage foreign ownership without compromising their national security or the interests of their people. In the United Kingdom, the parent companies of the five mobile operators are headquartered in France, Germany, Hong Kong, Spain and the United Kingdom (Cave \& Foster, 2010). In Australia, consumers have access to carriers, which are Australian, British, Singaporean and Hong Kong-based providers. Finally, in the United States, aside from their own national carriers, Americans can also get services from British and German firms. Canada has a foreign brand name MVNO, Britain's Virgin Mobile, however, Bell acquired full ownership of the stake of Virgin Mobile it did not already own in 2009 (BCE, 2009).

The case for lifting foreign ownership restrictions rests mostly on capital needs, which, especially for risk capital, are very likely to increase in the near future with the advent of new technologies and the increasing dissemination of wireless services. Given the significant costs of entry involved with purchasing spectrum, ample financial capital is needed for an entrant to fund the subsequent investments required to make their 
business viable. If the restrictions are lifted, given the market position held by the domestic incumbents, this may allow Canadian firms to grow to an internationally competitive size.

The second argument in favour of lifting foreign investment points to the ability to attract innovation and new technology. Canada's major carriers represent only a very small share of the world's communications sector (Industry Canada, 2010). Although Canadian carriers enjoy higher than average profits, on an international scale, there are telecom empires that operate worldwide. In addition, Canada is home to very few large high-tech companies, making us dependent on foreign tech manufacturers for handsets among other telecom related products. The argument has been made that closing ourselves to foreign investment puts Canadians at a disadvantage as a result of the missed opportunity to share in the benefits of the rapid technological change occurring in communications. If innovative foreign firms at the forefront of technological advancement are deterred from investing in Canadian communications infrastructure or carriers, Canada runs a risk of lagging behind.

\section{Experience of Entrants}

The conservative government in July 2007 convened a review panel, entitled the Competition Policy Review Panel (CPRP). The panel maintained the view that to ensure that domestic markets are healthy, and that unnecessary barriers to entry are minimized, domestic protection of telecom should be reduced or eliminated (CPRP, 2008). This followed the Liberal-appointed Telecommunications Policy Review Panel, which came to 
that conclusion in 2006 (TPRP, 2006). The Competition Bureau, a division of Industry Canada, has expressed the view that foreign ownership restrictions represent a considerable and at time insurmountable barrier to entry stating that protectionist policies towards foreign telecommunications investors, "[ [...] have served their purpose and are no longer necessary to harmonize Canadian policy with that of our global trading partners" (Competition Bureau Submission to the CPRP, 2007).

In response, in the Speech from the Throne on March 3, 2010, the conservative government announced its intention to"...open Canada's doors further to...foreign investment in key sectors, including the satellite and telecommunications industries, giving Canadian firms access to the funds and expertise they need." The government expressed their intention further in the 2010 Budget, which stated that "increasing foreign investment is an important way of strengthening market competition and attracting new capital and innovative ideas from abroad." However, in October 2013, the Canadian government did not look favourably on an offer from VimpelCom to buy out Wind Mobile's Canadian partner, Anthony Lacavera (Franklyn et al., 2013). Although the Minister did not issue a final decision under the Investment Canada Act (ICA), media sources suggested that the proposed transaction gave rise to national security concerns as a result of the Moscow based ownership of Vimpelcom Ltd. and Wind's use of Chinesesupplied technology in its wireless network infrastructure. The government subsequently denied Manitoba Telecom's attempt to sell its Allstream division under the national security provisions of the ICA to Accelero Capital. Accelero is headed by Naguib Sawiris, an Egyptian telecom financier who led the start-up of Canada's Wind Mobile as the original large scale investor. 
Investors have become wary of Canada's foreign investment restrictions. After declaring in the Speech from the Throne that Canada would open its doors to foreign investment in key sectors, including the telecommunications industry, the government blocked a handful of high-profile deals. ${ }^{5}$ This has created uncertainty surrounding Canada's position towards foreign investment. Maura Lendon, chief counsel for AT\&T Canada said to $\mathrm{CBC}$ that, "Canada has a reputation as being a challenging place for nonCanadians to carry on business" (CBC, Sep 10, 2008). There is speculation that this uncertainty and wariness of Canadian foreign policy towards investment is what deterred Verizon Communications from purchasing Wind after they had expressed interest in the company in June 2013 (Verizon, 2013).

This year, Wind's operations are close to breaking even in terms of earnings before interest, taxes, debt and amortization (Wind, 2014). However, Wind's lack of funding, limited coverage and spectrum, fewer network upgrades, and the fact that it still has just 3 percent of the national market years after launch present some potential future issues (CWTA, 2014). Wind needs a fresh infusion of capital, which has been challenging given the domestic attitude towards foreign interest in Canadian telecom.

In the previous section, I discussed the excessive barriers to entry that spectrum scarcity has created. Given the perpetual introductions of new technology in the mobile telecommunications market, capital requirements are high. Foreign ownership restrictions have made obtaining financial backing to develop a viable business difficult. In addition, despite the government taking a position to open Canada's doors to foreign

5 Alliant Techsystems' proposed acquisition of MacDonald Dettwiler and Associates' (MDA's) Information Systems Business in 2008 and BHP Billiton's hostile bid for Potash Corp in 2010 (Franklyn et al., 2013). 
investment, they have subsequently denied a number of high profile investors. This has created a climate of uncertainty and further deterred foreign investors from investing their capital in Canada. In the absence of liberalization of these restrictions and transparency surrounding the Canadian position toward foreign ownership it is difficult for an entrant to establish market position.

\subsection{Wireless Code of Conduct}

Given the challenges in establishing a fourth facility-based carrier as a competitor to discipline the telecommunications market, the CRTC took an alternative route through their recent Wireless Code of Conduct (2013). The two stated goals of the Wireless Code of Conduct (WCC) are (1) ensuring consumers are informed in order to make clear subscription decisions and (2) minimize costs to consumers who wish to make a subscription change to an alternative carrier. I will focus on the latter provisions of the WCC, which are more relevant to this thesis.

In general, switching costs can inhibit competition because they reduce consumers' incentives to switch suppliers in response to changes in prices. In a market such as the mobile telecommunications market, the customer incurs a cost when switching between providers even if the products are functionally identical. The cost to the consumer creates a disincentive to switch between providers when facing a price increase. The consumer switching costs therefore enhances market power over their subscribers which makes the firms current market share an important predictor of future profitability. The firms therefore face a decision between increasing their market share by lowering fees to attract new customers or increasing fees to gauge current subscribers 
while sacrificing market share in the process. I discuss these issues in detail in the next chapter.

Seeking to rectify the potential negative effects of switching costs, the CRTC introduced the following provisions in the WCC. Consumers can:

- terminate wireless contracts after two years without cancellation fees;

- cancel service before the end of the contract period, and the service provider must not charge the customer any fee or penalty other than the early cancellation charges (which are calculated according to the WCC requirements);

- have their cellphones unlocked after 90 days or immediately if they paid for the device in full at the rate specified by the provider; and

- return their cellphones, within 15 days and specific usage limits, if they are unhappy with their service.

The CRTC implemented these policies as they state that specifically in the telecommunications market, switching costs can have harmful effects in three ways. First, switching costs have the possible effect of making it difficult for new entrants to gain market share as they are forced to provide a fee that will compensate a consumer for the cost of switching from their previous provider. This presents an additional cost of entry that may make participating in these markets less profitable.

Second, switching costs reduce consumer mobility which may alleviate the pressure on carriers to compete. This could be a disincentive to offer competitive rates for consumers or it may be a disincentive to innovate and bring the most beneficial technology to consumers. 
Finally, switching costs may raise competitors' costs. As previously discussed, barriers to entering into Canadian wireless markets can be large. For an entrant to survive they would likely need to increase their subscription base to reach significant economies of scale and scope and compete on a level which would discipline incumbent prices.

\subsection{Conclusions}

This chapter provides some background on the wireless telecommunications market in Canada. We saw that, in order to promote competition, Industry Canada reserved spectrum for new entrants in the in 2008 during the Advanced Wireless Services (AWS) spectrum auction and placed limits on the amount of spectrum that a carrier could accumulate. After this auction, several new carriers entered the market. However, these new entrants have faced significant barriers since launching their wireless networks. In this chapter I outlined two of these major challenges entrants have faced, namely, spectrum scarcity and foreign ownership restrictions.

The most recent telecom policy implemented by the CRTC is the Wireless Code of Conduct (WCC). The CRTC attributes several negative effects that switching costs in the wireless industry present for consumers and new entrants. The WCC thus, seeks to reduce switching costs in order to promote competition in the wireless industry. The WCC also seeks to increase transparency surrounding mobile phone contracts.

While spectrum scarcity and foreign ownership restrictions are significant barriers to creating a more competitive wireless industry in Canada, my analysis will focus on the possible effects of the WCC. More specifically, I will focus on the provisions of the WCC that seek to reduce switching costs. In order to assess the possible effects of the 
WCC, I will first study a theoretical model in chapter 3 and then review the empirical literature on switching costs in the wireless industry in chapter 4 . These empirical studies allow me to suggest, in chapter 5 , regulatory provisions to maximize the gain from a reduction in switching costs. 


\section{CHAPTER 3:}

Theoretical Evidence

\subsection{Switching Cost Theory}

Economic literature has theorized extensively on the negative effects of switching costs on consumers (Farrell and Klemperer, 2007). It is widely perceived that switching costs make markets less competitive. From a theoretical perspective, however, the conclusion is not all that straightforward. Generally speaking, the theoretical studies have shown that the effects of switching costs on prices and welfare are dependent on market specific characteristics, such as, whether or not consumers are forward-looking, the size of switching costs, transaction costs, and so on . The mobile communications market, however, has some unique features in addition to switching costs such as network effects (Corrocher \& Zirulia, 2009; Doganoglu \& Grzybowski, 2007) and the potential for price discrimination (Laffont, Tirole, \& Rey, 1998). This can cause distortions that are absent in a conventional market and can result in favorable conditions for large firms (Koski \& Kretschmer, 2004; Shi, Chiang, \& Rhee, 2006).

After surveying competition in markets with switching costs, Klemperer (1995) identifies several main sources of switching costs. Following Klemperer's terminology, as it applies to the telecommunications market (1) compatibility costs (2) size of discount and (3) transaction costs are most prevalent switching costs. Compatibility costs would include operators' SIM-locking and phone locking practices. If a consumer wishes to switch providers they must incur the cost of unlocking a mobile device or in some cases purchase a new phone. Following the introduction of the WCC (2013), compatibility 
costs were reduced since early termination charges are now levied according to a formula specified by the CRTC. However, compatibility costs still exist since you are charged a fee, decided upon by the provider, for unlocking the device as mentioned in chapter 1.

Size of discount refers to discounts used in order to attract new subscribers such as handset subsidies, or discounts for calls within your network. The Canadian carriers use both of these tools, whereby handset subsidies are offered based on committing to a 12 or 24-month contract and operators offer free calling between family members if they all subscribe to the same network.

Finally, transaction costs are charged to a consumer when there is a breach by the consumer of their contract and termination fees are levied. This can again be seen in Canada where there is a cancellation fee levied in switching providers which is now regulated through the requirements of the WCC. In the absence of Wireless Number Portability (WNP) there would be an additional transaction cost involved in losing your current phone number when switching providers as the consumer is forced to inform all contacts of their change in number; a cost that is much larger in the case of commercial mobile phone customers.

Farrell and Klemperer (2006) further analyzed the level of competition in a market with switching costs and the presence of network effects. If products are incompatible with other networks ${ }^{6}$ both switching costs and network effects have the end result of locking consumers into their choice of network. Applying their theory to the mobile communications market, the consumer falls victim to changes in efficiency as they are already bound by their existing contract. This therefore gives the carrier ex post

\footnotetext{
${ }^{6}$ A locked mobile device would be an example of products that are incompatible with other networks.
} 
market power in the case of existing subscribers and over non-subscribers with network effects. As a result, in the early stages or with the advent of a new market segment, firms compete using price wars, introductory discounts and low ball pricing. It is possible for this initial period to compensate for the later cycle in which the firm has ex post market power, however, as Farrell and Klemperer explain, more often this market power results in a loss of efficiency and competition which favors the larger incumbent firms. They refer to this type of competition as incompatible competition.

Incompatible competition is susceptible to competitive forces in the beginning, but in the long run it tends toward monopolistic characteristics, at which point entry becomes difficult. Despite switching costs being encouraging of small-scale entry, they discourage competing for the marginal consumer. Additionally, network effects diminish incentives to cut prices especially if subscribers' expectations are dependent on past market shares.

On its face, it may seem that the obvious policy choice would be to reduce consumer switching costs as this is expected to result in a decrease in prices and an increase in consumer welfare. However, some theoretical studies argue that this is not always the case. Some have argued that WNP does not benefit consumers in all cases because it can make it difficult to determine who the provider is when placing a call therefore creating misinformation about termination charges (Aoki \& Small, 1999, 1999). In an analytical model, Aoki \& Small (1999) argued that the technological costs involved with implementing WNP may result in the consumer receiving less surplus following the reduction in switching costs. Buehler \& Haucap (2004) found that if it is difficult for a consumer to determine with which network their telephone number belongs then mobile 
operators may increase termination charges. This may exceed the consumer surplus generated from the reduction in prices due to the decrease in switching costs. There is much empirical evidence that has examined this question, and I will survey this literature in the next chapter. Furthermore, in a study of the effects of WNP Shi et al. (2006) found that a reduction in switching costs, while leading to a decrease in prices, may accelerate the gain in market share by the larger network.

Given the ambiguity in the theory surrounding the effects of a reduction in switching costs on the wireless telecommunications market, I seek to examine the effects of reducing switching costs on telecom. I will adapt the WNP model of Shi et al. (2006) and apply their model to alternative switching costs. I will use the switching cost involved in unlocking a mobile device as an example in my analysis. I obtain a result consistent with that of Shi et al. (2006) that a decrease in switching costs may make it more difficult for smaller firms to survive.

My model follows closely the model by Shi et al. (2006), but my results differ in two significant ways. First, a decrease in switching costs decreases the fixed fee paid by subscribers to the smaller firm but increases the fixed fee charged by the larger firm. Second, the impact of reducing unlocking fees on total industry profits, service valuation is dependent on the relative initial size of the two firms and the size of the remaining individual switching costs present in the market. This is consistent with empirical findings, which I will examine in the subsequent chapter.

Moreover, I expand on the examination by Shi et al. (2006) by exploring the effect on consumer welfare. I find that consumers who belong to the larger network are made worse off by eliminating fees for unlocking devices as a result of paying increased 
fixed fees. The welfare effects on consumers who belong to the smaller network are dependent on the relative difference in the size of the two firms and the remaining switching costs that an individual subscriber would face in switching to the larger network. The aggregate effect is also depending on the size of the remaining individual switching costs and the relative difference in initial market share between the two firms.

\subsection{The Model}

Consistent with Shi et al. (2006) my model characterizes the competition between two differentiated wireless carriers, firm $a$ and firm $b$, in a market of $\mathrm{N}$ consumers. Let $\theta_{a}$ and $\theta_{b}$ represent firm $a$ and $b$ 's initial market share. I further assume that the carriers are asymmetric, specifically $\theta_{a}>\theta_{b}$. The model is a variation of a model of Bertrand Competition in which the two wireless carriers set their prices at stage 1 , and subsequently, consumers make subscription decisions at stage 2 . The decision made by the consumer is whether to remain with her current carrier or switch to the alternate service provider. Suppose that the marginal consumer, who is indifferent between remaining in his current network and switching to the alternate carrier, belongs to network $l(l=a$ or $b)$. Then carrier $k(k \neq l)$ will retain all subscribers and may or may not gain market share by attracting the marginal consumer $l$. The network sizes of firms $l$ and $k$ are $\mathrm{N} \theta_{l}$ and $\mathrm{N} \theta_{k}$ where $\theta_{l}+\theta_{k}=1$. I assume that if a consumer decides to switch to network $k$, she will be subject to a switching cost denoted by $\psi_{l k}$.

We will assume that customers of either carrier can communicate with each other; however, following Shi et al. (2006) there is an interconnection charge levied on the 
carriers via a "cost recovery method regulated exogenously by the government." As in Laffont et al. (1998b) and Shi et al. (2006) I will refer to calls within carriers as "on-net calls" and calls between carriers as "off-net calls." Let $c$ and $\eta c$ be each network's marginal costs for on-net and off-net calls respectively where $\eta>1$. Carriers apply discriminatory pricing to their respective networks, which consists of (1) a fixed access fee, $F_{l,}$ and $F_{k}(2)$ a price for on-net calls, $p_{l l}$ and $p_{k k}$, and (3) a price for off-net calls, $p_{l k}$, $p_{k l}$. In accordance with a Bertrand model there is no collusion or cooperation between firms in setting prices and prices are set independently and simultaneously to each other.

\subsubsection{Stage 2: Consumer's Subscription Decision}

\section{Consumer Valuation of Mobile Networks}

Consumers value the ability to communicate with others who are within and outside of their network; however, they only value communicating with individuals with which they have a positive social tie. That is, a consumer who subscribes to network $a$ does not necessarily value communication with all other subscribers of network $a$ and $b$, they only derive positive utility from communication with the select consumers within their social circle. Let $n$ represent the number of consumers within the individual's social network, or in other words, the number of consumers that an individual derives positive utility from the ability to contact. As in Laffont et al. (1998b) and Shi et al. (2006) I assume that consumers are uniformly distributed between the two networks, or a

\footnotetext{
${ }^{7}$ Shi et al. (2006) point to OFTA (1998) for a detailed example of the cost recovery method or (Armstrong et al. (1996) and Laffont et al. (1998a, b) for an alternate approach for modeling connection costs between firms.
} 
"uniform calling pattern." This means that given a firm $l$ or $k$ 's market share, $\sigma_{l}$ or $\sigma_{k}$, a subscriber to network $l$ or $k$ has positive ties with $n \sigma_{l}$ and $n \sigma_{k}$ respectively. ${ }^{8}$

To remain consistent with prior literature I assume that utility $u(q)$ is monotonically increasing and concave with respect to $q$, the quantity of communication. The quantity of communication consists of the quantity of on-net calls, $q_{l l}$ and $q_{k k}$, and off-net calls, $q_{l k}$ and $q_{k l}$. A consumer's in network $l$ values off-net communication according to:

$$
\begin{gathered}
v\left(p_{l k}\right)=\max _{q_{l k}} u\left(q_{l k}\right)-p_{l k} q_{l k} \\
\text { where } l, k=a \text { or } b .
\end{gathered}
$$

Equation (1) shows that given a positive tie between consumers, an individual who subscribes to network $l$ chooses their quantity of communication where their marginal utility is equal to the price of communicating with an individual in network $k$. Similarly, valuation of a consumer in network $k$ values on-net communication according to:

$$
\begin{array}{r}
v\left(p_{k k}\right)=\max _{q_{k k}} u\left(q_{k k}\right)-p_{k k} q_{k k} \\
\text { where } k=\text { a or } b .
\end{array}
$$

Valuation of on-net communication may be different than that of off-net communication since their valuation of network communication is network dependent.

\footnotetext{
${ }^{8}$ Note that I maintain the balanced-traffic assumption meaning that the number of on-net calls is determined by the firm's market share. As detailed in Laffont et al. (1998) this relies on the assumption that consumers who are in frequent contact do not coordinate in order to belong to the same network.
} 
Following the notation of Shi et al. (2006), let $v\left(p_{l k}\right)=v_{l k}$ and $v\left(p_{l l}\right)=v_{l l}$ and the same for on and off net valuations for network $k$.

Now to aggregate a consumer's total valuation of communication services, denoted by $\omega_{l}$ and $\omega_{k}$, I obtain the following equations:

$$
\begin{aligned}
& \omega_{l}=n \sigma_{l} v_{l l}+n \sigma_{k} v_{l k}-\mathrm{F}_{l} \\
& \omega_{k}=n \sigma_{k} v_{k k}+n \sigma_{l} v_{k l}-\mathrm{F}_{k}(3) \\
& \quad \text { where } l, k=a \text { or } b \text { and } l \neq k .
\end{aligned}
$$

From equations (2) and (3) I can see that across a consumer's entire social network their valuation is dependent on the number of positive social ties, the respective market share of each firm, their valuation of on versus off net communication and the fixed fee. A consumer who subscribes to the larger firm derives a greater amount of utility since they have a larger number of social ties within their network. An extreme example would be if one carrier, for example $k$, monopolized the market so that $n \sigma_{l}=0$. Subscribers to network $k$ would no longer pay the higher fees associated with the higher marginal cost of off-net calls since their entire social network would be within the same carrier. This does not imply that consumers would be better off in a monopoly market with a single carrier as the monopolist is free to charge whatever fixed fee they so choose.

\section{Network Subscription Decision}


When choosing between networks, the consumer takes into consideration their valuation of communication with each network, outlined above in equations (2) and (3), and the cost of switching between carriers. Recall that the cost to a consumer to switch from network $l$ to $k$ is denoted by $\psi_{l k}$. Therefore, the value of subscription if the consumer remains with the same network is $\omega_{l}$ or $\omega_{k}$, but the value of subscription to the consumer who switches to network $k$ is $\omega_{k}-\psi_{l k}$. It follows that for the marginal consumer, the switching cost must satisfy:

$$
\begin{array}{r}
\psi_{l k}^{*}=\omega_{k}-\omega_{l} \\
\text { where } k=\text { a or } b, k \neq l .
\end{array}
$$

Any existing customer of network $l$ whose switching cost is less than $\psi_{l k}^{*}$ will switch to network $k$, while other customers will remain in network $l$.

Here I diverge from Shi et al. (2006) to assume that switching costs vary across consumers and are uniformly distributed in the interval $[s, \Psi+s] .{ }^{9}$ This specification captures two types of switching costs. Parameter $s$ represents the common switching costs that every consumer who switches networks has to incur, such as the cost of unlocking a phone from a particular carrier. Moreover, each consumer also incur individual-specific switching costs which are uniformly distributed in $[0, \Psi]$.

\footnotetext{
${ }^{9}$ Shi et al. (2006) as in Shaffer and Zhang (2000) assumed switching costs varied across consumers and were uniformly distributed in the interval $[0, \Psi]$. They modeled a change in switching costs by a decrease in $\Psi$. We assume that switching costs vary across consumers and are uniformly distributed on the interval $[s, \Psi+s]$. We model a change in switching costs that apply to all consumers, such as unlocking a mobile device by a change in s. Individuals also face customer-specific switching costs that range over the interval $[0, \Psi]$.
} 
Note that for switching to occur in equilibrium $\psi_{l k}^{*} \geq s$. Given these assumptions, network $l$ and $k$ 's market shares can be determined as follows:

$$
\begin{gathered}
\sigma_{l}=\theta_{l}-\frac{\theta_{l}\left(\psi_{l k}^{*}-s\right)}{\Psi} \\
\sigma_{k}=\theta_{k}+\frac{\theta_{l}\left(\psi_{l k}^{*}-s\right)}{\Psi}
\end{gathered}
$$

$$
\text { where } l, k=a \text { or } b, k \neq l \text {. }
$$

As indicated previously, consumers choose a network independently with no collusion or cooperation. Moreover, I follow Shi et al. to assume that consumers have perfect foresight of each network's equilibrium market shares. Combining equations (2)(6) I derive the following market shares:

$$
\begin{gathered}
\sigma_{l}=\left[\Psi \theta_{l}-\theta_{l} n\left(v_{k k}-v_{l k}\right)-\theta_{l}\left(\mathrm{~F}_{l}-\mathrm{F}_{k}-s\right)\right] \cdot\left[\Psi-\theta_{l} n\left(v_{l l}+v_{k k}-v_{l k}-v_{k l}\right)\right]^{-1}, \\
l, k=\text { a or } b \text { and } l \neq k . \\
\sigma_{k}=\left[\Psi \theta_{k}-\theta_{l} n\left(v_{l l}-v_{k l}\right)-\theta_{l}\left(\mathrm{~F}_{k}-\mathrm{F}_{l}+s\right)\right] \cdot\left[\Psi-\theta_{l} n\left(v_{l l}+v_{k k}-v_{l k}-v_{k l}\right)\right]^{-1}, \\
l, k=\text { a or } b \text { and } l \neq k .
\end{gathered}
$$

To ensure an interior solution where both networks have positive market shares in equilibrium, it is assumed that $\Psi>\theta_{l} n\left(v_{l l}+v_{k k}-v_{l k}-v_{k l}\right) .{ }^{10}$ Consistent with Shi et al. (2006), (7) and (8) indicate that a network's market share is dependent on their variable and fixed fees, and prior network sizes. The first term shows that with a larger

\footnotetext{
${ }^{10}$ As shown in Shi et al. (2006 p 32), if this condition is not satisfied, a corner solution would arise in which any network carrier can capture the entire market with a small decrease in its fixed fee.
} 
value of $\Psi$ it is more difficult for a customer to switch networks thus reducing the number of customers who switch networks. The third term intuitively shows that the firm's market share is decreasing in its own fixed fee and increasing in its rival's fixed fee. It is also notable that the market share of the firm containing the marginal consumer, firm $l$, is increasing in $s$ but the market share of the firm which stands to gain the marginal consumer, firm $k$, is decreasing in $s$.

$$
\begin{aligned}
& \frac{d \sigma_{l}}{d s}=\frac{\theta_{l} / 3}{\Psi-\theta_{l} n\left(v_{l l}+v_{k k}-v_{l k}-v_{k l}\right)}>0 \\
& \frac{d \sigma_{k}}{d s}=\frac{\frac{-\theta_{l}}{3}}{\Psi-\theta_{l} n\left(v_{l l}+v_{k k}-v_{l k}-v_{k l}\right)}<0
\end{aligned}
$$

This result is interesting as it is somewhat counter intuitive. You would expect that given a decrease in switching costs the larger firm would lose market share as consumers would switch providers. However, this result implies that the network that that marginal consumer belongs to is more dependent on switching costs to retain market share as their marker share is increasing with larger switching costs.

\subsubsection{Stage 1: Carrier Pricing Decision}

At stage 1 the two carriers independently and simultaneously determine their pricing scheme. When doing so, each carrier maximizes its profit taking the rival firm's pricing strategy and market share as given. The firm's own market shares are given by equations (7) and (8). The carrier choses prices according to the profit maximization problem below: 


$$
\begin{gathered}
\max _{p_{l l}, p_{l k}, \mathrm{~F}_{l}} \pi^{l}=N \sigma_{l}\left[n \sigma_{l}\left(p_{l l}-c\right) q\left(p_{l l}\right)+n \overline{\sigma_{k}}\left(p_{l k}-\eta c\right) q\left(p_{l k}\right)+\mathrm{F}_{l}\right. \\
\max _{p_{k k}, p_{k l}, \mathrm{~F}_{k}} \pi^{k}=N \sigma_{k}\left[n \sigma_{k}\left(p_{k k}-c\right) q\left(p_{k k}\right)+n \bar{\sigma}_{l}\left(p_{k l}-\eta c\right) q\left(p_{k l}\right)+\mathrm{F}_{k}\right.
\end{gathered}
$$

The firm $l$ earns profits from the fixed fee $\mathrm{F}_{l}$ variable fees from on and off net calls respectively according to, $n \sigma_{l}\left(p_{l l}-c\right) q\left(p_{l l}\right)+n \overline{\sigma_{k}}\left(p_{l k}-\eta c\right) q\left(p_{l k}\right)$. Firm $k$ earns profits from its fixed fee $\mathrm{F}_{k}$ and its variable fees from on and off net calls respectively according to, $n \sigma_{k}\left(p_{k k}-c\right) q\left(p_{k k}\right)+n \bar{\sigma}_{l}\left(p_{k l}-\eta c\right) q\left(p_{k l}\right)$. Their profits increase with their number of subscriber's $N \sigma_{l}$ and $N \sigma_{k} . \mathrm{N}$ is the size of the market, which could be interpreted as the penetration rate. As the number of mobile phones in a market increases, so too does N. This would increase both firms' profits. Each firm's profits, as one would expect, are also increasing in their own market share.

\subsubsection{Equilibrium Conditions}

Taking first order conditions of (9) and (10) and applying Roy’s identity I find that the resulting variable fees are equal to their marginal costs, which is consistent with that of Shi et al. (2006):

$$
p_{i l}=p_{k k}=c, p_{l k}=p_{k l}=\eta c
$$

Laffont et al. (1987b) obtain the same result in their model of network competition with price discrimination. Condition (11) suggests that on-net fee is lower than the off-net fee. 
Valuation of on-net communication may be different than that of off-net communication since their valuation of network communication is network dependent. In other words $q\left(p_{l k}\right) \leq q\left(p_{l l}\right)$ and $q\left(p_{k l}\right) \leq q\left(p_{k k}\right)$ since the variable fee is lower with intracommunication than with intercommunication. This, in turn, implies that two consumers in the same network will communicate more with each other than with consumers in other networks. ${ }^{11}$ It follows that $v_{l l}>v_{l k}$ and $v_{k k}>v_{k l}$. Let $\Delta v=v_{l l}-$ $v_{l k}$ and/or $\Delta v=v_{k k}-v_{k l}$ which given equation (11) can also be written as $\Delta v=v(c)-$ $v(\eta c)$. This difference in valuations can be interpreted as the "on-net discount" (Shi et al. 2006).

To then solve for the equilibrium fixed fee, I substitute $\Delta v$ and the variable fees in (11) into equations (7) and (8) as well as profit maximization problems (9) and (10) to get:

$$
\begin{array}{r}
\max _{\mathrm{F}_{l}} \pi^{l}=N \sigma_{l} \mathrm{~F}_{l}\left(9^{\prime}\right) \\
\text { where } \sigma_{l}=\frac{\theta_{l} \Psi-\theta_{l} n \Delta v-\theta_{l}\left(\mathrm{~F}_{i}-\mathrm{F}_{j}-s\right)}{\Psi-2 \theta_{l} n \Delta v} \\
\text { where } \sigma_{k}=\frac{\theta_{k} \Psi-\theta_{l} n \Delta v-\theta_{l}\left(\mathrm{~F}_{k}-\mathrm{F}_{l}+s\right)}{\Psi-2 \theta_{l} n \Delta v}
\end{array}
$$

Taking the first-order conditions and solving for the equilibrium fixed fees, I obtain the following:

\footnotetext{
${ }^{11} \mathrm{We}$ will see in the subsequent section that this result is consistent with empirical findings (Swann \& Birke, 2006).
} 


$$
\begin{aligned}
& \mathrm{F}_{l}^{*}=\frac{1+\theta_{l}}{3 \theta_{l}} \Psi-n \Delta v+\frac{s}{3} \\
& \mathrm{~F}_{k}^{*}=\frac{1+\theta_{k}}{3 \theta_{l}} \Psi-n \Delta v-\frac{s}{3}
\end{aligned}
$$

As previously mentioned, the firms generate profits through their fixed fees and the variable fees on on-net and off-net calls. The results of the profit maximization problems (9) and (10) show us that the variable fees will be equal to their marginal costs. Given the variable fees, I solve profit maximization problem (9') and (10') according to marker shares ( $\left.7^{\prime}\right)$ and ( $\left.8^{\prime}\right)$ to determine the equilibrium fixed fees according to equations (12) and (13). This is summarized in the proposition below.

Proposition 1: In a pure strategy equilibrium, network variable fees are equal to the marginal costs. The equilibrium fixed fees are given in equations (12) and (13).

As pointed out in (4) in section 3.2.1, in order for switching to occur $\psi_{l k}^{*} \geq s$. I have derived the equilibrium fixed fees and market shares above on the premise that $\psi_{l k}^{*} \geq s$. From (4) I know that:

$$
\omega_{k}-\omega_{l} \geq s
$$

Substituting in expressions (2) and (3) for $\omega_{k}$ and $\omega_{l}$ and simplifying I get:

$$
n \Delta v\left(\sigma_{k}-\sigma_{l}\right)+\left(F_{l}-F_{k}\right) \geq s
$$


Substituting in market shares according to equations (6') and (7') and equilibrium fixed fees according to equations (11) and (12) I obtain the following condition:

$$
\frac{\left(\theta_{k}-\theta_{l}\right)}{\theta_{l}}\left[\Psi-\theta_{l} n \Delta v\right]>s
$$

We know that $\Psi>2 \theta_{l} n \Delta v$ and therefore that $\Psi>\theta_{l} n \Delta v$ and $s \geq 0$, it follows that $\theta_{k}>\theta_{l}$. Given the assumption $\theta_{a}>\theta_{b}$, I can conclude that $k=a$ and $l=b$. In other words, the marginal consumer is in network $b$.

We can see from (12) and (13) that a decrease in switching costs $s$ therefore decreases the fixed fee charged by the firm containing the marginal consumer $l$ but increases the fixed fee charged by firm $k$. As such, I can further conclude that:

Proposition 2: Reducing the fee for unlocking a mobile device increases the fixed fee of the larger firm and decreases the fixed fee of the smaller firm.

Condition (14) implies that $\psi_{l k}^{*}>s$. You'll also recall equations (5) and (6) below from section 3.2.1 which I have updated given that I now know $l=b$ and $k=a$.

$$
\begin{aligned}
& \sigma_{b}=\theta_{b}-\frac{\theta_{b}\left(\psi_{l k}^{*}-s\right)}{\Psi} \\
& \sigma_{a}=\theta_{a}+\frac{\theta_{b}\left(\psi_{l k}^{*}-s\right)}{\Psi}
\end{aligned}
$$

We can infer from equations (5) and (6) that $\sigma_{b}<\theta_{b}$ and that $\sigma_{a}>\theta_{a}$. This means that firm $a$ is larger initially and stands to gain the marginal consumer from firm $b$. Firm $b$ is 
the smaller firm initially and stands to lose market share to firm $a$. As such, firm $a$ will gain market share in equilibrium and further widen the gap between the larger and smaller firm. I can therefore further conclude that:

Proposition 3: Since $\psi_{l k}^{*}>s$ there exists a unique pure strategy equilibrium where $\sigma_{b}^{*}<\theta_{b}$ and $\sigma_{a}^{*}>\theta_{a}$. Additionally, we know that this will increase the larger firm's market share further, thus widening the gap between the two firms market shares.

Solving the system of equations ( $\left.7^{\prime}\right)-(13)$ I obtain the following market shares for firm $l$ and $k$ :

$$
\begin{gathered}
\sigma_{b}=\frac{\left[\frac{1+\theta_{b}}{3}\right] \Psi-\theta_{b} n \Delta v+\theta_{b} \frac{s}{3}}{\Psi-2 \theta_{b} n \Delta v} \\
\sigma_{a}=\frac{\left[\frac{1+\theta_{a}}{3}\right] \Psi-\theta_{b} n \Delta v-\theta_{b} \frac{s}{3}}{\Psi-2 \theta_{b} n \Delta v}
\end{gathered}
$$

As described above, the market share of the firm containing the marginal consumer, firm $l$, is increasing in $s$ but the market share of the firm which stands to gain the marginal consumer, firm $k$, is decreasing in $s$. I now know that network $l=b$ and represents the smaller network and network $k=a$ and represents the larger network. This result implies that the smaller network that the marginal consumer belongs to is more dependent on switching costs to retain market share as their marker share is increasing with larger switching costs. In a submission by the Commissioner of Competition to the CRTC (Feb 2013) they state that one of the harms that switching costs cause is an inability for new entrants to attract customers. However, the above results implies that high switching costs 
are duly important in order for new entrants to retain their existing customers since with a decrease in switching costs, the larger firm gains market share.

\subsubsection{Equilibrium Analysis}

The total value of communication across both networks can be expressed as follows:

$$
\begin{gathered}
V=N\left\{\sigma_{b}\left[n \sigma_{b} v(c)+n\left(1-\sigma_{a}\right) v(\eta c)\right]+\sigma_{a}\left[n \sigma_{a} v(c)+n\left(1-\sigma_{b}\right) v(\eta c)\right]\right\} \\
=N n\left[v(c)-2 \Delta v \sigma_{b} \sigma_{a}\right]
\end{gathered}
$$

Taking the derivative with respect to switching costs:

$$
\begin{gathered}
\frac{\partial V}{\partial s}=-2 \Delta v\left[\left\{\frac{\left[\frac{1+\theta_{b}}{3}\right] \Psi-\theta_{b} n \Delta v+\theta_{b} \frac{s}{3}}{\Psi-2 \theta_{b} n \Delta v}\right\}\left\{\frac{-\frac{\theta_{b}}{3}}{\Psi-2 \theta_{b} n \Delta v}\right\}\right. \\
\left.+\left\{\frac{\left[\frac{1+\theta_{a}}{3}\right] \Psi-\theta_{b} n \Delta v-\theta_{b} \frac{s}{3}}{\Psi-2 \theta_{b} n \Delta v}\right\}\left\{\frac{\frac{\theta_{b}}{3}}{\Psi-2 \theta_{b} n \Delta v}\right\}\right] \\
\frac{\partial V}{\partial s}=-2 \Delta v\left\{\frac{\theta_{b}}{3\left(\Psi-2 \theta_{b} n \Delta v\right)}\right\}\left\{\frac{\left[\theta_{a}-\theta_{b}\right] \Psi-2 \theta_{b} s}{3\left(\Psi-2 \theta_{b} n \Delta v\right)}\right\}
\end{gathered}
$$

We obtain the condition:

$$
\begin{gathered}
\text { If } s>\frac{\left(\theta_{a}-\theta_{b}\right) \Psi}{2 \theta_{b}} \text { then } \frac{\partial V}{\partial s}>0, \text { or } \\
\text { If } s<\frac{\left(\theta_{a}-\theta_{b}\right) \Psi}{2 \theta_{b}} \text { then } \frac{\partial V}{\partial s}<0 .
\end{gathered}
$$

Combining condition (14) with the above expression (17) I find that: 


$$
\begin{gathered}
(14)<(17) \text { if } \Psi<2 \theta_{b} n \Delta v, \text { or } \\
(14)>(17) \text { if } \Psi>2 \theta_{b} n \Delta v .
\end{gathered}
$$

However, I have previously assumed that $\Psi>2 \theta_{b} n \Delta v$ therefore (13) $>$ (14); I also know $S<(13)$. As a result there are two possible outcomes:

$$
\begin{aligned}
& \text { If }(14)>(17)>s \text { then } \frac{\partial V}{\partial s}>0, \text { or; } \\
& \text { If }(14)>s>\text { (17) then } \frac{\partial V}{\partial s}<0 .
\end{aligned}
$$

Therefore, it is not clear whether or not service valuations will increase or decrease in response to a reduction in $s$. Whether we will see an increase or decrease is dependent on the initial size of the firms' relative market shares and the customer specific switching costs as seen in (14). I summarize the result in the following proposition:

Proposition 4: Reducing customer-switching costs by reducing the cost of unlocking a device will increase services valuations if $\frac{\left(\theta_{k}-\theta_{l}\right)}{\theta_{l}}\left[\Psi-\theta_{l} n \Delta v\right]>s>\frac{\left(\theta_{a}-\theta_{b}\right) \Psi}{2 \theta_{b}}$ but decrease services valuations if $\frac{\left(\theta_{k}-\theta_{l}\right)}{\theta_{l}}\left[\Psi-\theta_{l} n \Delta v\right]>\frac{\left(\theta_{a}-\theta_{b}\right) \Psi}{2 \theta_{b}}>s$.

It is not obvious why one possible outcome of Proposition 4 is that with a decrease in switching costs consumer valuation may increase. I know from Proposition 3 that eliminating unlocking fees will increase network $a$ 's market share and thus widen the gap between the two firms. As in Shi et al. (2006) the increase in the larger firm's market share results in a larger number of consumers enjoying on-net discounts which therefore 
can result in an increase in the total valuation for communication services. Whether or not this is the case depends on the initial relative size difference between the two firms and what individual switching costs each consumer faces.

Firms earn their profits only from the fixed access fees since the variable fees cover the marginal costs. Therefore, aggregate profits are as follows:

$$
\Pi=N\left[\sigma_{b} \mathrm{~F}_{b}+\sigma_{a} \mathrm{~F}_{a}\right]
$$

Substituting equations (11) and (12) for $\mathrm{F}_{b}$ and $\mathrm{F}_{a}$ and simplifying, I obtain:

$$
\Pi=N\left\{\frac{1+\sigma_{b} \theta_{b}+\sigma_{a} \theta_{a}}{3 \theta_{b}} \Psi-n \Delta v+\left(\sigma_{b}-\sigma_{a}\right) \frac{s}{3}\right\}
$$

Substituting equations (15) and (16) for $\sigma_{l}$ and $\sigma_{k}$ I get the following expression:

$$
\begin{gathered}
\Pi=N\left\{\frac{\Psi}{3 \theta_{b}}\left[1+\frac{\theta_{b}\left[\frac{\theta_{b}+1}{3} \Psi-\theta_{b} n \Delta v+\frac{\theta_{b} S}{3}\right]}{\Psi-2 \theta_{b} n \Delta v}+\theta_{a} \frac{\left[\frac{\theta_{a}+1}{3} \Psi-\theta_{b} n \Delta v-\frac{\theta_{b} s}{3}\right]}{\Psi-2 \theta_{b} n \Delta v}\right]\right. \\
\left.-n \Delta v+\left[\frac{\frac{\theta_{b}-\theta_{a}}{3} \Psi+\frac{2 \theta_{b} s}{3}}{\Psi-2 \theta_{b} n \Delta v}\right]\left[\frac{S}{3}\right]\right\}
\end{gathered}
$$

Then, differentiating with respect to s I derive the following expression:

$$
\frac{\partial \Pi}{\partial s}=N \frac{\left[2 \Psi\left(\theta_{b}-\theta_{a}\right)+4 \theta_{l} s\right]}{9\left(\Psi-2 \theta_{l} n \Delta v\right)}
$$

From this expression I are able to obtain the following conditions: 


$$
\begin{gathered}
\text { If } s>\frac{\left(\theta_{a}-\theta_{b}\right) \Psi}{2 \theta_{b}} \text { then } \frac{\partial \Pi}{\partial s}>0, \text { or } \\
\text { If } s<\frac{\left(\theta_{a}-\theta_{b}\right) \Psi}{2 \theta_{b}} \text { then } \frac{\partial \Pi}{\partial s}<0 .
\end{gathered}
$$

This is the same condition as condition (17) above. Following the same process, I combine with condition (14) and find that:

$$
\begin{gathered}
(18)<(14) \text { if } \Psi<2 \theta_{b} n \Delta v, \text { or } \\
(14)>(18) \text { if } \Psi>2 \theta_{b} n \Delta v .
\end{gathered}
$$

However, I have previously assumed that $\Psi>2 \theta_{b} n \Delta v$ therefore (14) $>$ (18); I also know $S<(14)$. As a result, there are two possible outcomes:

$$
\begin{aligned}
& \text { If }(13)>(15)>s \text { then } \frac{\partial \Pi}{\partial s}<0 \text {, or; } \\
& \text { If }(13)>s>\text { (15) then } \frac{\partial \Pi}{\partial s}>0 .
\end{aligned}
$$

Total industry profits are therefore dependent on the size of the remaining individual switching costs in the market and the relative initial difference in size between the two firms.

Proposition 5: Reducing customer-switching costs by reducing the cost of unlocking a device will increase industry profits if $\frac{\left(\theta_{k}-\theta_{l}\right)}{\theta_{l}}\left[\Psi-\theta_{l} n \Delta v\right]>\frac{\left(\theta_{a}-\theta_{b}\right) \Psi}{2 \theta_{b}}>s$ but decrease industry profits if $\frac{\left(\theta_{k}-\theta_{l}\right)}{\theta_{l}}\left[\Psi-\theta_{l} n \Delta v\right]>s>\frac{\left(\theta_{a}-\theta_{b}\right) \Psi}{2 \theta_{b}}$. 


\subsubsection{Consumer Welfare}

I will now examine the effect that the elimination of unlocking fees would have on consumer welfare for a subscriber of each network. You will recall expressions (2) and (3) from section 3.2.1.

$$
\begin{aligned}
& \omega_{b}=n \sigma_{b} v_{b b}+n \sigma_{a} v_{b a}-\mathrm{F}_{b} \\
& \omega_{a}=n \sigma_{a} v_{a a}+n \sigma_{b} v_{a b}-\mathrm{F}_{a}
\end{aligned}
$$

Substituting in the equilibrium market shares and taking the derivative with respect to $s$ I get the following results:

$$
\frac{\partial \omega_{k}}{\partial s}=\frac{\theta_{l} n \Delta v}{\Psi-2 \theta_{l} n \Delta v}+\frac{1}{3}>0
$$

We see that consumers in the larger network are made worse off by a reduction in the unlocking fee due to the increase in fixed fee. Things are not as straight forward for the consumer belonging to network $b$ :

$$
\frac{\partial \omega_{l}}{\partial s}=\frac{\theta_{l} n \Delta v}{\Psi-2 \theta_{l} n \Delta v}-\frac{1}{3}
$$

There are two possible conditions:

$$
\begin{gathered}
\frac{\partial \omega_{l}}{\partial s}>0 \text { if } \Psi>5 \theta_{l} n \Delta v ; \text { or } \\
\frac{\partial \omega_{l}}{\partial s}<0 \text { if } \Psi<5 \theta_{l} n \Delta v .
\end{gathered}
$$

The welfare of those belonging to the smaller network is dependent on the size of the remaining switching costs in the market. With a larger value of $\Psi$ welfare decreases with 
a reduction in the unlocking fee and with a smaller value of $\Psi$ welfare increases with a reduction in the unlocking fee.

Proposition 6: Consumers in the larger network are made worse off by a reduction in the unlocking fee. Consumers in the smaller network are made worse off if $\Psi>5 \theta_{l} n \Delta v$ but better off if $\Psi<5 \theta_{l} n \Delta v$.

We will now examine the effect that the reduction of unlocking fees would have on consumer welfare in aggregate.

$$
\begin{gathered}
W=N\left(\sigma_{b} \omega_{b}+\sigma_{a} \omega_{a}\right) \\
=N n\left[v(c)-2 n \Delta v \sigma_{b} \sigma_{a}-\sigma_{a} F_{a}-\sigma_{b} F_{b}\right]
\end{gathered}
$$

Then, I substitute in the equilibrium market shares and fixed fees for firm $a$ and take the derivative with respect to $s$ :

$$
\begin{array}{r}
\frac{\partial W}{\partial s}=\frac{-\theta_{b}}{3\left(\Psi-2 \theta_{b} n \Delta v\right)}\left[\frac{\sigma_{b}-\sigma_{a}}{2} \Psi+\frac{\theta_{b}-\theta_{a}}{3 \theta_{b}} \Psi+\frac{4 s}{3}\right] \\
-\frac{2 \theta_{b} n \Delta v}{3\left(\Psi-2 \theta_{b} n \Delta v\right)}\left[\frac{\frac{\sigma_{a}-\sigma_{b}}{3} \Psi-\frac{2 \theta_{b} s}{3}}{\Psi-2 \theta_{b} n \Delta v}\right]
\end{array}
$$

I obtain the condition:

$$
\text { If } s>\frac{\left(\sigma_{a}-\sigma_{b}\right)}{2 \theta_{b}} \Psi \text { then } \frac{\partial W}{\partial s}<0, \text { or }
$$




$$
\text { If } s<\frac{\left(\sigma_{a}-\sigma_{b}\right)}{2 \theta_{b}} \Psi \text { then } \frac{\partial W}{\partial s}>0 \text {. }
$$

Combining with condition (14) I find that:

$$
\begin{gathered}
(19)<(14) \text { if } \Psi>\theta_{b} n \Delta v, \text { or } \\
\text { (19) }>\text { (14) if } \Psi<\theta_{b} n \Delta v .
\end{gathered}
$$

However, I have previously assumed that $\Psi>2 \theta_{b} n \Delta v$ therefore $(17)<(13)$. I also know that $S<(13)$. As a result there are two possible outcomes:

$$
\begin{aligned}
& \text { If }(14)>(19)>s \text { then } \frac{\partial W}{\partial s}<0, \text { or; } \\
& \text { If }(14)>s>(19) \text { then } \frac{\partial W}{\partial s}>0 .
\end{aligned}
$$

The aggregate welfare is therefore dependent on the size of the remaining individual switching costs in the market and the relative initial difference in size between the two firms.

Proposition 5: Reducing customer-switching costs by reducing the cost of unlocking a device will increase aggregate welfare if $\frac{\left(\theta_{k}-\theta_{l}\right)}{\theta_{l}}\left[\Psi-\theta_{l} n \Delta v\right]>\frac{\left(\sigma_{a}-\sigma_{b}\right)}{2 \theta_{b}}>s$ but decrease aggregate welfare if $\frac{\left(\theta_{k}-\theta_{l}\right)}{\theta_{l}}\left[\Psi-\theta_{l} n \Delta v\right]>s>\frac{\left(\sigma_{a}-\sigma_{b}\right)}{2 \theta_{b}}$. 
There are three different factors at play here: (1) the increase in fixed fees charged by the larger firm, (2) the decrease in fixed fees charged by the smaller firm, and (3) the increase in on-net variable discount to customers belonging to the larger firm.

\subsubsection{Conclusions}

An interesting equilibrium result I obtained was that a decrease in switching costs decreases the fixed fee paid by subscribers to the smaller firm but increases the fixed fee charged by the larger firm. In addition, consumer welfare is decreasing for the subscribers of the larger firm. The remaining results were dependent on the initial relative size difference of the carriers and the remaining switching costs that individuals may face. My model predicts that the larger carriers will increase their market share and the smaller carrier will lose market share. This suggests that a reduction in switching costs by reducing the fee for unlocking a mobile device may actually further concentrate the market. However, it is unclear what would be the welfare impact of such a change. As such, further empirical analysis is needed to answer these outstanding questions. 


\section{CHAPTER 4:}

Empirical Evidence

After studying the theoretical model in chapter 3, I will now review the empirical literature on switching costs in the wireless telecommunications industry. The studies I will review below cover a large number of countries around the world. Ideally, I would like to have empirical evidence on the role of switching costs in the Canadian wireless markets, but such studies are not available. Regardless, the studies I chose have useful implications for Canada as there are many issues that are common across wireless markets such as network effects and price discrimination. In addition, I have chosen studies of countries which have similar market characteristics. For example, congruent with the Canadian market, the Japanese wireless market can also be characterized as an oligopolistic market structure. The purpose of this review is to complement the theoretical analysis in chapter 3 and provide an empirical basis for the policy discussions in chapter 5 .

If one surveys the empirical literature on switching costs in the mobile telecommunications market, he will find that the majority of work has focused on a widespread policy called Wireless Number Portability (WNP). Wireless number portability allows a consumer to keep her telephone number when switching from one mobile network carrier to the next. This gives the customer the ability to avoid the costs associated with giving up her telephone number and communicating the new telephone number to all of her contacts. If a consumer's phone number is associated with her work this cost can be significant as there may be costs involved with having to print new business cards, or missing valuable calls from contacts who do not have the new number. 
Another policy that has been studied empirically is SIM unlocking. A SIM lock is a capability which is built into mobile phones by the manufacturer. Network carriers can use this capability to restrict the use of a particular phone to a particular network carrier. In some countries, you can purchase phones without a SIM lock which allows you to insert a SIM card belonging to the network of your choice. SIM unlocking has been studied to a much lesser extent than WNP. This is because this policy is a newer practice and is much less common at this time.

The results of WNP have been varied due to heterogeneous market conditions \& differing regulations. There are several studies, which claim WNP had the desired effect of promoting competition (Bühler, Dewenter, \& Haucap, 2006; Park, 2011), whereas others report that the effect of introducing WNP on overall welfare is ambiguous (Aoki \& Small, 1999; Haucap \& Buehler, 2004; Shi et al., 2006). I will outline several empirical studies of WNP to examine those circumstances in which WNP was or was not effective in achieving its aim of promoting competition. In addition, I examine the case of Japan introducing service portability in the form of unlocking SIM cards in 2011.

This chapter is divided into five sections. This is based on five important factors which I have extrapolated from the literature that have had a potential impact on the effectiveness of WNP or SIM unlocking in practice. They are as follows:

1. the portability period and fee;

2. the presence of network effects;

3. hidden costs to consumers;

4. the magnitude of remaining switching costs; and

5. incentives for innovation. 
The first four factors draw from studies of WNP, the fifth factor that I will examine comes from a study of SIM unlocking. The SIM unlock example is similar to the example I used in my analysis which was phone unlocking. This practice may require constructing similar incentives for handset manufacturers to ensure the policy benefits consumers. I will explore each of these factors using empirical evidence from the experience of various countries.

\subsection{Portability Period and Fee}

The portability period or porting period is the length of time a consumer must wait before their mobile number is functional with a new carrier. The portability fee or porting fee is the cost associated with carrying a phone number through the switch. As one can intuitively conclude, these are both factors which affect a consumer's willingness to switch between mobile carriers. As a result, the porting period and fee have the potential to affect how suitable WNP is in its purpose of reducing switching costs to consumers. The dampening effect of WNP on switching costs depends on porting period and fee.

There has been considerable examination of the effectiveness of the implementation of WNP in European countries. WNP has varied significantly across these countries with respect to their methods of implementation. As such I will be examining an empirical study by Asimakopoulos and Sánchez (2012) which looks at the European mobile communications market as a whole and draw conclusions based on the varying results in this sample. 


\subsubsection{Lessons from WNP in the Europe}

Asimakopoulos and Sánchez (2012) looked at 13 countries in the EU from 20002009 studying the effect of the porting period and fees on customer churn rates ${ }^{12}$ instead of pricing levels. They chose to use the churn rate to reflect a growing trend in the mobile telecommunications market. OECD countries have experienced increasingly high penetration rates, for example, between January 1998 and June 2003 the total number of subscribers in Germany grew by about 700\% (Doganoglu \& Grzybowski, 2007). This does not leave a large portion of the market untapped. As a result, the markets focus has shifted to retaining as many of their subscribers as possible while competing for rival networks' subscribers (Kim \& Yoon, 2004). Therefore, the churn rate accurately reflects customer switching behavior and is a key variable for carriers in the mobile industry.

Asimakopoulos and Sánchez found that a higher porting period and a higher porting fee negatively affect the churn rate, meaning, the cost to a consumer of switching providers increases with a longer porting period and a higher porting fee. By the end of 2009, the majority of carriers in the EU countries no longer charged porting fees and the average porting period was around 4.4 days. Table 4.1 .1 shows the decrease in porting fees and porting periods from the introduction of WNP to 2009. In 2011, new regulation was introduced by the European commission following a review of the rules governing the electronic communications sector, which mandates a porting period of one day in all member states of the EU.

Asimakopoulos and Sánchez suggest that the negative relationship between the porting period and fee and churn rates may be explained by corporate strategy to oppose

\footnotetext{
${ }^{12}$ Churn rate is the number of subscribers of a particular service who chose to discontinue their subscription during a given time period.
} 
regulation that increases competition in the mobile telecommunications industry. Table 4.1.1 shows that initially, the porting period and fee was higher in many countries than it is now. As an initial attempt to maintain market position, a carrier may lengthen the period that it takes to transfer your mobile number and/or increase fees associated with WNP. However, the decrease in porting period and fee may also be attributed the significant initial costs to a carrier of implementing WNP.

Buehler, Haucap and Dewenter (2006) came to a similar conclusion as Asimakopoulos and Sanchez (2012) in looking at the relationship between the number of portings and the porting period and fee, rather than the churn rates and the porting period and fee. They found that higher charges and longer porting periods tend to lead to higher consumer switching costs and therefore to a lower use of WNP. Interestingly, they comment that porting speed is depending on the technology used to reroute calls as well as the willingness of networks to accelerate the porting process. They point out that the donor network does not have strong incentives to move the process forward.

These results tell us that stringent rules surrounding the implementation of WNP policies is required for them to be effective. Both Buehler et al. and Asimakopoulos and Sanchez conclude that in the absence of regulation, the donor network is not incentivized to facilitate WNP for consumers. The effectiveness of a switching cost strategy such as WNP is dependent on the regulations by which it is implemented. The regulators should dictate the operators cost recovery method, dictate maximum time length for implementation and regulate charges levied to consumers. It is important for these regulations to incentivize operators to adopt the preferred technology to do so where applicable. 


\subsection{Network Effects}

A network effect is the effect that a user of a product can have on the demand of that product . In other words, the more people that use a good or service, the more valuable that good or service gets. For example, the telephone became more and more valuable as more people purchased telephones, resulting in a network effect. In Shi et al. (2006) and in my own model, I saw that a discriminatory pricing scheme results in an onnet discount, which benefits the larger firm by creating a network effect. As a result, the larger firm can charge a higher fixed access fee due to the savings generated from a smaller relative number of off-net calls, which are more costly to the provider. In Shi et al. with a high fixed fee the larger firm would lose some market share to the smaller firm. In my model, on the other hand, the network effect is exacerbated since even with a high fixed fee, the larger firm still gains market share over the smaller firm. In this section, I will survey the empirical findings surrounding the existence of a network effect in telecom, and the potential implications this can have on market power of incumbents.

\subsubsection{Evidence from the German Telecom Market}

After a few years of exponential growth, in Germany in 2003 there were more than 60 million wireless phone subscribers. This reflects a 700\% growth in subscribers between 1998-2003 (Doganoglu \& Grzybowski, 2007). There are many potential causes of this exceptional growth. The most obvious would be a decrease in prices, which allowed a larger amount of consumers to be able to afford mobile telecommunication technology. During the same time period, the index of prices for mobile services calculated by the German Statistical Office fell by about $41 \%$. It is unclear how much of the growth of subscribers can be attributed to the price decrease or whether there is 
another factor effecting subscriber growth. Doganoglu and Grzybowski (2007) tried to determine whether this increase in subscribers can be attributed to a network effect. They test using churn rates, the first difference of observed subscription levels and firmspecific prices to determine if network effects may offer some explanation for this intense growth. They found that the described penetration levels could be reached without network effects only if prices were drastically lower than they were in actuality. Moreover, without network effects, if prices remained as observed, the penetration of mobiles would be lower than it was in actuality by an increment of at least $50 \%$. Figure 4.2.1 depicts the industry growth with and without network effects. The results suggest that network effects play a significant role in the proliferation of mobile telephony in Germany.

As described in this study, network effects have a significant impact on subscription decisions. This implies that, policy makers cannot ignore network effects and attribute changes in demand entirely to price fluctuations. A failure to account for network effects would result in a miscalculation of price elasticities and allow for incorrect conclusions to be drawn with regards to the competitiveness of the industry.

\subsubsection{Evidence from Japan's Telecom Market}

Ida \& Kuroda (2009) analyze the demand for mobile telephones second generation $(2 \mathrm{G})$ and third generation (3G) networks in Japan using a discrete choice model called a mixed-logit model. Similar to the Canadian market, the Japanese market is oligopolized by three incumbent network providers. The largest network in Japan is called NTT and they possess $56.1 \%$ of the market, the closest network AU possesses $26.0 \%$ and finally the last is DoComo with $17.9 \%$. Ida and Kuroda (2009) examine the 
substitution patterns of the demand for mobile telephone services between providers of second versus third generation networks. They found that a $1 \%$ increase in the basic monthly charge of NTT's $3 \mathrm{G}$ service decreases its choice probability by $0.8 \%$. Interestingly, this increases the probability of choosing NTT's $2 \mathrm{G}$ service by $0.5 \%$ but increases the probability of choosing AU's 3 G service only by $0.1 \%$. This provides evidence of a strong network effect in Japan since the closest substitute for NTT's 3G service is NTT's $2 \mathrm{G}$ service, rather than AU's 3G service.

\subsubsection{Evidence from UK Telecom Market}

Birke and Swann (2006) estimates two different models to determine the role of network effects in the consumer's choice of mobile phone operators in the UK. First, they compare the number of on-net and off net calls and find that comparatively, the number of off-net calls falls as the fee for off-net calls increases. Figure 4.2.3 depicts the development of the ratio between on and off net calls. Interestingly, they find that even in the absence of a difference in price between on and off net calls there are still a larger number of on net calls, providing evidence that there may also be a network effect even in the absence of a difference in price between on and off net calls. Birke and Swan suggest that consumers may coordinate in choosing networks in order to take advantage of on-net discounts. Their second model provides insight into consumer choice of network provider. The study finds evidence that an individual's choice of network subscription is influenced by the number of subscribers to each operator, suggesting that consumers show a preference towards networks with a larger number of subscribers.

Their results are consistent with those of my model and suggest that the high price of off-net calls can not only be a result of higher marginal costs but also be a significant 
source of market power. As described in Chapter 3, Klemperer and Farrell (2006) found that in a market with switching costs and network effects, incumbents can use this market power to deter entry, which results in a magnification of incumbent power. This was echoed in my model, where the incumbent was able to increase fixed fees and still gain market share.

\subsubsection{Evidence from the Swedish Telecom Market}

Srinuan (2010) examined the impact of WNP regulation in Sweden, using econometric models with data from the period 2003-2009. The results of the inquiry show that the implementation of WNP was not sufficient to significantly reduce switching costs and increase the level of competition. He finds that switching costs remained high for those who subscribe to the incumbent carrier. He attributes the main reason for the ineffectiveness of WNP is the existence of what he refers to as terminationbased price discrimination i.e. increasing on-net/off-net price differentials. Srinuan finds that the current system creates an artificial network effect that favor the larger mobile operators since subscribers of the larger network are less likely to switch due to a lower average cost of calling. This was a result present in my model where the increase in the market share of the larger incumbent can be attributed, partially, to a larger number of on-net calls which creates a discount for their subscribers. This further widens the price differential between entrants and incumbents.

Siruan suggests that in order to overcome this problem, the telecom regulator needs to revise the mobile regulations surrounding termination rates that are currently in place. At the moment, termination charges are levied based on fully allocated costs, which he believes, exacerbates the network effects by benefitting the larger networks. He 
recommends a focus on considering bill-and-keep for mobile termination charges. ${ }^{13}$ This would eliminate the incentive for the network to price discriminate between on- and offnet calls. By reducing network effects it can reduce the advantage held by the larger incumbent carriers and therefore reduce barriers to entry for new carriers.

\subsection{Hidden Costs}

The introduction of number portability has two effects on the consumers costs of subscription. First, it reduces the switching cost by avoiding the cost of informing all contacts of your change in phone number. Second, as I discussed in chapter 3 it increases the marginal cost of making calls because additional technology must be introduced in order to reroute calls and establish connections (Aoki \& Small, 1999; Haucap \& Buehler, 2004). I will discuss further how this increase in cost is generated and review the literature regarding the potential for such costs to be charged to the consumer in an alternative manner thus diminishing the welfare improving effects of a reduction in switching costs.

The introduction of number portability requires several modifications to the network and business organization of the participating networks (Aoki \& Small, 1999). There are three different potential ways to provide WNP; call forwarding, terminating intelligent network (terminating-IN) and originating intelligent network (originating-IN). The relative sizes of the costs of the three methods are difficult to quantify and each imposes a different mix of fixed and variable costs. This can be attributed to the fact that

\footnotetext{
${ }^{13}$ Bill and Keep is "a pricing scheme for the two-way interconnection of two networks under which the reciprocal call termination charge is zero - that is, each network agrees to terminate calls from the other network at no charge" (OECD, 2005).
} 
they vary based on the proportion of calls directed to ported numbers and the locations of such calls.

Call forwarding is a low cost option but cannot sustain a large number of porting numbers and therefore will likely need to be replaced by another operating system in the long run. Originating network has high fixed set up costs but low variable cost whereas terminating network has low fixed set up costs but high variable costs. Figure 4.3 shows the average cost functions for terminating-IN and originating-IN. The choice of porting technology is greatly affected by the estimated number of portings in a market. The number of portings varies greatly across the OECD, making it difficult to estimate the most efficient method for a particular carrier. Therefore, depending on a carrier's choice of technology, they may suffer a financial loss. There is some evidence of carriers then passing on this cost through hidden fees, usually in the form of inflated termination charges. Thus, depending on set-up costs it is difficult to determine the aggregate effect of WNP.

\subsubsection{Evidence from WNP in Europe}

Buehler and Haucap (2004) provided an analytical framework based on the argument that WNP creates a reduction in tariff transparency since the prefix of the mobile number no longer indicates the originating network. If customers can no longer identify the originating network of a call, this creates an incentive for operators to increase termination charges since customers can only observe the average of charges. Dewenter and Haucap (2005) explored this finding empirically using a sample of 48 mobile operators from 17 European countries. Their analysis shows signs of exaggerated termination rates due to the negative pricing externality generated by a lack of 
transparency surrounding termination charges. They build on this analysis by examining asymmetric carriers and find that the smaller carriers have higher termination rates than their larger competitors. They explain that smaller operators will charge higher termination rates than larger operators since they have a relatively smaller impact on the weighted average price. As a result, they are able to increase their prices without a major negative effect on quantity demanded. This is consistent with my model where subscribers to the larger firm have a lower average cost of calling as a result of the on-net discount of subscribing to the larger firm.

Buehler, Haucap, and Dewenter (2006) surveyed the literature on the implementation of WNP in Europe. They found that in addition to minimizing porting speed and fees, it was important to increase tariff transparency in order for WNP to be ultimately beneficial to consumers. As previously stated, the evaluation of costs associated with the introduction of WNP is difficult. For example, if mobile operators adopt originating-IN there are high set-up costs but decreasing average costs. Since there is uncertainty about the number of portings that will occur in the future when WNP is first introduced, it is difficult to estimate what to charge the consumer. The number of portings varies greatly by country as seen in Table 4.3.1 with the charges for porting being a significant factor.

It can therefore be assumed, that the market is unlikely to generate efficient charges for consumers since networks have monopoly power over their already locked-in customers, which will have already been allocated a mobile number. Without tariff transparency, if the set up cost is not recovered terminating charges can be inflated. It is therefore important to regulate the method by which termination charges are levied to 
avoid these costs being levied on the consumer rather than incurred by the carrier. at least in the period following the introduction of WNP. For customers that have subscribed to a network and obtained a mobile number before the introduction of $\mathrm{WNP}^{14}$, Buehler, Haucap and Dewenter (2006) have argued for a price cap regime starting from the current average cost of porting. The two objectives are to incentivize the networks to adopt the most efficient technology while still maintaining low fees to consumers.

They determine, however, that tariff transparency can be enhanced through regulation. They suggest different approaches to increasing transparency, which have been introduced in Europe. For example, acoustic signals which alert a consumer when they are making an off-net call, toll-free enquiry numbers, or verbal signals which inform the customer about tariffs when making a call. Interestingly, after surveying the literature Buehler, Haucap and Dewenter (2006) found that in contrast to the predictions of their analytical model in their 2004 paper, virtually all cost-benefit analyses indicate that the overall effect of WNP was positive, with larger benefits to those countries who had reduced porting time, fee and increased tariff transparency.

\subsubsection{Evidence from WNP in the United States}

Park (2011) examines the price response by mobile network carriers after the introduction of WNP. He found that wireless prices decreased in the advent of number portability, but not uniformly across all users. Low, Medium, and High volume users received discounts of $0.97 \%, 4.84 \%$ and $6.81 \%$ respectively. The results suggest that those users with plans that indicate they are high-volume users of mobile services

\footnotetext{
${ }^{14}$ It is conceivable that those who subscribe to a network after the implementation of WNP may be offered WNP at efficient prices in order to incentivize consumers to sign a contract (Bühler, Dewenter, \& Haucap, 2006).
} 
benefited more than casual low-volume users. However, Park also found evidence that some wireless carriers have imposed additional monthly surcharges on their customers to recover the costs of number portability. Park's estimations indicate that each customer pays $\$ 0.53$ per month as a 'price' for having the option of porting their number should they chose to switch networks. Since low-volume users did not enjoy as much price decrease as medium-high users but pay the same 'price' to have the option of porting numbers, high-volume users benefitted more from the policy. In fact, the very low end users are actually worse off due to number portability since they paid an equal share of number portability costs while there was a slight increase in prices for their plans after number portability. He did however find that the aggregate effect was still a reduction in overall price.

An interesting feature of the US market, is that new consumers and renewing consumers are offered the same menu of plans and various types of promotions such as a reduction in the monthly access fee and there are no penalties to renewing customers. Therefore, there is little distinction between new and old customers (Park, 2011). This allows less opportunity to price discriminate in a way that reduces network effect (Farrell \& Klemperer, 2007). This is not the case in all markets including the Canadian market.

\subsection{Size of Remaining Switching Costs}

In my theoretical model, we saw that total profits, communication valuations, and welfare were dependent on the size of the remaining switching costs in the market. There are many potential sources of switching costs in the telecommunications sector. Switching costs can include time, money and the psychological impact on consumers of switching 
mobile operator. There is the time cost in researching the different providers and plans and going through the actual switching process. There are costs involved with porting your number as we previously saw with WNP. Then there's paying out device subsidies, termination fees, etc. There are many different costs involved when switching networkservice providers. As such, even with a decrease in one potential source of consumer cost, such as reducing the charge for unlocking devices, there is not necessarily a benefit to consumers unless the reduction is significant enough to still induce them to switch. We saw with my constraint $\psi_{l k}^{*} \geq s$ that the switching cost must be sufficiently reduced in order to induce customers to switch. In this section, I will outline examples where WNP was not as effective as possible due to high remaining switching costs in the market.

\subsubsection{Lessons from WNP in the United States}

In the United States, it was initially estimated that 30 million subscribers would switch within the first year of WNP's introduction. In the three years since WNP was initiated, however, only 10 million subscribers have switched from one carrier to another (FCC, 2005). Furthermore, small mobile carriers have not added subscribers significantly, whereas the top five big carriers have all added subscribers with WNP (Shin \& Kim, 2008).

Shin (2006) studied the effect of WNP by focusing on subscribers' perceptions of WNP. He looked at their beliefs regarding remaining costs after the introduction of WNP and subscribers' switching behaviors surrounding WNP. Statistical analyses in this study reveal that subscriber's perceived switching barrier is still high, discouraging subscribers from switching carriers. There is evidence that carriers have turned to new subscriber lock-in strategies that make subscribers stay with current carriers. 
Shin and Kim (2008) investigated switching barriers post-WNP further and their results imply that WNP has not directly contributed to the regulators' goal of removing switching barriers that have been prevalent in the subscribers' perceptions in a significant way. Instead, WNP has indirectly enhanced switching barriers through increased subscriber lock-in strategies and tactics. There was a positive impact for consumers as operators engaged in aggressive customer retention strategies, including better deals on upgrade handsets, incentives for longer contracts, better customer service, and increased network spending.

\subsubsection{Lessons from WNP in Japan}

In October 2006, Japan introduced WNP to promote competition in the country's highly restrictive mobile phone market. However, a year after this service was introduced, the utilization rate remained only 3\% (Ida \& Kuroda, 2009). Measuring customers' willingness to pay, Ida and Kuroda found that one contributing factor is that users still cannot transfer other services such as e-mail addresses, music data, game applications, and handsets between operators. There are significant time costs involved with getting a new e-mail address or re-downloading your music. The consumers' willingness to pay for increased service portability greatly exceeded the current costs of switching providers. Therefore, although they would be willing to pay more for the ability to port their music, data, and game applications, this is not an option. This indicates that there are time costs involved in changing network-carriers which discourage switching. For example, it takes time to establish a large music library. Therefore, customers were less willing to switch carriers if they could not bring their music. They were willing to pay between $\$ 1-2$ a song in order to have the ability to port 
the music to their new carrier, despite the fact that it is cheaper to purchase the songs originally. Although number portability decreased switching costs, the significant remaining time costs involved with switching providers continued to discourage switching in the market.

\subsubsection{Lessons from WNP in Korea}

Switching costs in Korea have been lowered since WNP and there is evidence that the WNP promoted competition. However, there still remain significant switching costs, which continue to lock-in consumers thus impeding significant decreases in customer fees. In a study by Lee et al. (2006), the authors used a conjoint analysis to evaluate the price effects and consumer valuation since the introduction of WNP. They found that although switching costs have been reduced, $88.6 \%$ of the population would not switch to another provider without some compensation. This gives us an indication that the inconvenience posed by changing mobile numbers is only among the components of switching costs. Consumers still require additional compensation in order to be lured to a new provider. However, given that customers are still reluctant to switch, there is little incentive for larger incumbent carriers to provide these incentives. This is consistent with my model since welfare effects, profits and consumer valuations are in part dependent on the size of the remaining switching costs in the market.

Lee et al. suggests that one potential way to decrease switching costs is through efficiency gains. For example, in order to decrease uncertainty surrounding switching providers, Lee et al. suggest an independent third-party organization to evaluate the levels of quality and price of different networks and communicate this information to the public. This reduces the time cost spent by consumers researching the various networks. Further, 
they suggest that the regulatory body should compel service providers to establish an easy and simple brand-switching system. They use the example of retail electricity market in the United Kingdom, where the regulatory body created a website through which consumers can change retail electricity providers. Finally, they suggest a common billing system for all service providers so that subscribers who wish to terminate their subscription to one service in favor of another can easily settle the remaining charges by means of a common bill. These changes minimize the inconveniences incurred by switching, similar to WNP, which will decrease the overall cost to consumers.

\subsection{Incentivizing Carriers and Handset Manufacturers}

In this section, I look at a different potential policy, namely, SIM unlocking. SIM unlocking is not a widespread practice like WNP thus far. I will examine SIM unlocking in the Japanese context. In this particular case, the regulation dictates that the devices are originally sold with the SIM cards unlocked upon customer request at no cost to the user. In practice, this means that if the consumer chooses to switch carriers, they simply have to purchase a new SIM card from the new carrier rather than a new device.

As previously stated, the Japanese market is characterized by three incumbent carriers and very stringent regulations surrounding the telecommunications market. In an attempt to increase competition in the market, Japan's regulatory authorities, the Ministry of Internal Affairs and Communication (MIC) introduced WNP in 2006. One year later the utilization rate was only at $3 \%$. In an effort to further facilitate service portability, MIC released guidelines suggesting that mobile operators release their Subscriber Identity Module (SIM) for mobile devices (Ida \& Kuroda, 2009). This changed the 
dynamic between handset manufacturers, consumers and operators. Operators place less merit on attracting consumer through exclusive handset offerings and focus more on emphasizing attractive qualities of their networks and pricing. Handset manufacturers are less tied to a particular carrier as they are not subsidized for developing handsets with their new found independence. Consumers benefit from the freedom of choice of operator and mobile device, however, they may suffer from increased prices and or decreased quality on the part of the handset manufacturers. This is speculative given that this practice has only recently put into place; therefore they do not know what the outcome will be yet.

It is interesting to remember that SIM unlocking and mobile device unlocking is linked to issues of vertically integrated markets. It is important to understand how device unlocking will change the behaviour of handset vendors, third party content providers and their relationship with carriers. In implementing regulation, supply-side behaviours should be considered.

\subsection{Conclusions}

In this chapter I have reviewed the empirical literature on switching costs in the wireless telecommunications industry. The policies examined in this literature were Wireless Number Portability (WNP) and SIM unlocking. As is the goal with the implementation of the Wireless Code of Conduct (WCC), these regulations were introduced in order to reduce switching costs and increase competition in the wireless market. We saw that empirical findings have almost unanimously found that the overall effect for consumers of WNP is positive (Bühler et al., 2006). What is debated is the 
regulatory framework whereby the gain from a reduction in switching costs is maximized. In this chapter we considered several different considerations in designing a regulatory framework that would maximize the benefits of a policy which reduces switching costs in mobile communications.

To summarize, given that there is a disincentive for the carriers to implement policies which reduce switching costs, the effectiveness of policy such as WNP is dependent on the regulations by which it is implemented. Important factors to consider, drawn from the research on WNP, are regulations surrounding the appropriate cost recovery method used by operators, the appropriate technology to be adopted and measures to increase transparency surrounding charges levied on consumers. To be most effective, regulations must seek to minimize total switching costs and take advantage of any possible efficiency gains.

In the next and final chapter, I will use the insights from my theoretical analysis and the empirical studies as a guide to suggest regulatory provisions to maximize the gain for consumers from a reduction in switching costs. 


\section{CHAPTER 5:}

\section{Conclusions and Policy Recommendations}

Until recently, the federal government has focused their efforts on assisting the introduction of a fourth facility-based carrier with a goal of disciplining the currently elevated telecom rates. We saw in chapter 2 that the results have not been as promising as hoped thus far, with one potential entrant in bankruptcy proceedings and another having been bought out by an incumbent carrier. In response, the CRTC took a different approach by introducing the Wireless Code of Conduct (WCC) in 2013. To reduce consumer-switching costs, the code mandated contract provisions such as handset unlocking, restrictions on contract length and a reduction in termination fees. In this thesis, I have examined the effects of such contract provisions on carriers and consumers, both theoretically and empirically.

Specifically, I have modified an analytical model by Shi et al. (2006) to investigate the effectiveness of promoting competition through a reduction in consumer switching costs, such as the elimination of the unlocking fee for mobile phones. I found that, consistent with Shi et al., a reduction in switching costs may accelerate the gain in market share by the larger network. My results however, differ in two significant ways. First, a decrease in switching costs decreases the fixed fee paid by subscribers to the smaller firm but increases the fixed fee charged by the larger firm. Second, the impact of the reduction in switching costs on total industry profits is dependent on the size of the remaining switching costs present in the market and the relative difference in size between the firms initially. 
Moreover, I have extended the analysis by Shi et al. (2006) in exploring the effect on consumer welfare. Consumers who belong to the larger network are made worse off by eliminating fees for unlocking devices as a result of paying increased fixed fees. The aggregate welfare effects and the welfare effects of consumers who belong to the smaller network are dependent on the size of the remaining switching costs that a subscriber would face in switching to the larger network and the initial relative size of the carriers. Consumers in the smaller network are made worse off if the remaining costs of switching providers are high and better off if the remaining cost of switching providers are low.

In the preceding chapters I have reviewed theoretical and empirical evidence to determine the effect on the wireless communications market of a decrease in switching costs. I have seen that decreasing switching costs does not unambiguously reduce prices and improve welfare for consumers. There are many different conditions, which indicate the factors that should be considered when implementing market regulations. Given the results of the analytical model, I investigated empirical research of switching costs and found evidence that supported the conclusions of my model. From this evidence I will make several policy suggestions for future consideration below.

As previously stated, the Canadian regulatory bodies have shifted their policy focus to diminishing switching costs and increasing consumer awareness with the establishment of the Wireless Code of Conduct (WCC) in 2013. The CRTC states that switching costs present an additional cost of entry to non-incumbents as they are forced to provide a low fee to compensate a consumer for switching providers. My model indicates that with a decrease in switching cost the new entrant will decrease their fixed fee further. The smaller carrier is more dependent on the switching costs to retain their 
subscribers and generate revenue. A reduction in switching costs, as shown by my model and echoed by empirical evidence makes it more difficult for a small carrier to survive and results in more favorable conditions for the larger network (Haucap \& Dewenter, 2005; Shi et al., 2006; Shin \& Kim, 2008; Srinuan, 2010; Swann \& Birke, 2006). However, this does not necessarily mean that reducing switching costs is a negative outcome for consumers.

We have seen that the challenges faced by non-incumbent carriers are significant and have been insurmountable thus far. Spectrum scarcity has resulted in extreme barriers to entry with the initial costs incurred through purchasing spectrum at inflated rates as a result of spectrum scarcity. Restrictions on foreign ownership have made it difficult for new entrants to find financial support to compete with incumbents when there are innovations in the industry such as the upgraded LTE network. For a new entrant to survive, it would likely need to increase its subscription base to reach significant economies of scale and scope and compete on a level which would discipline incumbent prices. Even if the ownership restrictions are lifted, investors still may continue to shy away from the Canadian market given the uncertainty surrounding Canada`s position towards foreign investment. Similarly, even if the CRTC increased auction and trade flexibility to allocate spectrum more efficiently, this may not be significant enough for a new entrant to reach a level capable of disciplining the incumbents.

Given this reality, the policy shift toward stimulating competition between incumbent firms may be warranted. As we have seen, one way that this has been done is by reducing consumer switching costs. Switching costs reduce consumer mobility, which may alleviate the pressure on carriers to compete. This could be a disincentive to offer 
competitive rates for consumers or it may be a disincentive to innovate and bring the most beneficial technology to consumers. Empirical findings have almost unanimously found that the overall effect for consumers of Wireless Number Portability (WNP) is positive (Bühler et al., 2006). What is debated is the regulatory framework whereby the gain from a reduction in switching costs is maximized. My survey of recent empirical findings has yielded some important implications for future policy discussions.

Given that incumbents are less incentivized to adhere to policies which reduce consumer switching costs, stringent regulation is required to ensure policies achieve the desired effect. We saw with WNP, that a mandated porting speed and fee were important to stimulate competition and maximize the usage of mobile number porting. Similar considerations need to be specified for regulation in the future. In the WCC the CRTC mandates that a mobile device be unlocked by a carrier within 90 days or immediately if the device subsidy has been paid in full. The charge for the service however is, "at the rate specified by the provider." In order to increase the effectiveness of this policy, maximum charges for unlocking a device should be specified.

In my model we saw the presence of network effects, which are the source of the disadvantage faced by new entrants. Subscribers to the larger network enjoy a larger amount of on-net discounts since there are more of their social network within their carrier. This allows the incumbent to charge a higher fixed fee as consumers have a lower average coast of calling which makes them less willing to switch networks. To remedy the lock-in effect created by this incumbent advantage, Srinuan (2010) suggests a billand-keep method where the operators agree to terminate calls from other networks at no 
charge. This solution is worth investigating as it could reduce the advantage held by the larger incumbent carriers and level the playing field for the new carriers.

Regulations such as device unlocking and WNP present additional costs to operators who as profit maximizing agents will attempt to pass these costs on to consumers to maximize producer surplus. There are additional costs to operators associated with unlocking devices therefore charges for unlocking are necessary, however, these charges should be transparent and we should guard against hidden fees. In the case of device unlocking, if the phone was not locked initially, then there would be no costs to networks. This would avoid the potential issue of hidden fees as there are no costs to the operator. Given that currently the devices are still locked, charges are necessary to cover the costs to the network associated with the unlocking of devices.

We have seen that in the case of WNP hidden fees can be levied through termination charges if there is a lack of transparency surrounding the originating network. Buehler, Haucap and Dewenter (2006) have argued for a price cap regime starting from the current average cost of porting to incentivize the networks to adopt the most efficient technology while still maintaining low fees to consumers. They further suggest different approaches to increasing transparency, such as acoustic signals, which alert a consumer when they are making an off-net call.

With the case of hidden fees, the appropriate regulation to incentivize operators to implement the policy in such a way that it will maximize benefits to consumers will vary. Important factors to consider, drawn from the research on WNP, are regulations surrounding the appropriate cost recovery method used by operators, the appropriate technology to be adopted and measures to increase transparency surrounding charges 
levied on consumers. One should also consider the effect of the policy on related industries. As we saw in the case of SIM unlocking in Japan, relationships with suppliers or related industries can be altered by policy implementation and therefore should be taken into account.

Finally, although WNP had a positive impact on consumers, the prevalence of other remaining switching costs in the market reduced the potential benefits of this policy. Switching costs must be minimized to the maximum extent possible to induce the incumbent providers to compete for market share more aggressively. 


\section{References}

Aoki, Reiko, and John Small. "The Economics of Number Portability: Switching Costs and Two-Part Tariffs." University of Auckland, Dept. of Economics Working Paper, 1999. http://www.researchgate.net/publication/46473986 The Economics_of_Number_Portabi lity_Switching_Costs and Two-Part_Tariffs/file/60b7d51a6183876354.pdf.

Asimakopoulos, Grigorios, and Belén Usero Sánchez. "Regulation and Competition in the European Mobile Communications Industry." Telecommunications Policy 36, no. 3 (2012): 187-96.

Bühler, Stefan, Ralf Dewenter, and Justus Haucap. "Mobile Number Portability in Europe." Telecommunications Policy 30, no. 7 (2006): 385-99.

Bühler, Stefan, and Justus Haucap. "Mobile Number Portability." Journal of Industry, Competition and Trade 4, no. 3 (2004): 223-38.

Cave, Martin, and Adrian Foster. Solving Spectrum Gridlock. C.D. Howe Institute, 2010.

Corrocher, Nicoletta, and Lorenzo Zirulia. "I Me and You and Everyone We Know: An Empirical Analysis of Local Network Effects in Mobile Communications." Telecommunications Policy 33, no. 1 (2009): 68-79.

Degryse, H. A., J. M. C. Bouckaert, and T. Provoost. "Enhancing Market Power by Reducing Switching Costs." Economics Letters 114, no. 3 (2012): 359.

Doganoglu, Toker, and Lukasz Grzybowski. "Estimating Network Effects in Mobile Telephony in Germany.” Information Economics and Policy 19, no. 1 (2007): 65-79.

Farrell, Joseph, and Paul Klemperer. "Coordination and Lock-In: Competition with Switching Costs and Network Effects." Handbook of Industrial Organization. Vol. 3. Elsevier B.V, 2007.

Harbord, D., and M. Pagnozzi. 'Network-Based Price Discrimination and 'Bill-and-Keep' vs. 'Cost-Based' Regulation of Mobile Termination Rates.” Review of Network Economics 9, no. 1 (January 1, 2010).

Haucap, Justus, and Stefan Buehler. "Mobile Number Portability." Journal of Industry, Competition and Trade 4, no. 3 (2004): 223-38.

Haucap, Justus, and Ralf Dewenter. "The Effects of Regulating Mobile Termination Rates for Asymmetric Networks." European Journal of Law and Economics 20, no. 2 (2005): 18597. 
Ida, Takanori, and Toshifumi Kuroda. "Discrete Choice Model Analysis of Mobile Telephone Service Demand in Japan." Empirical Economics 36, no. 1 (2009): 65-80.

Kim, H., and C. Yoon. "Determinants of Subscriber Churn and Customer Loyalty in the Korean Mobile Telephony Market.” Telecommunications Policy 28, no. 9/10 (2004): $751-65$.

Klemperer, Paul D. "Competition When Consumers Have Switching Costs." The Review of Economic Studies 62, no. 4 (1995): 515-39.

Koski, Heli, and Tobias Kretschmer. "Survey on Competing in Network Industries." Journal of Industry, Competition and Trade 4, no. 1 (2004): 5-31.

Laffont, Jean-Jacques, Jean Tirole, and Patrick Georges Rey. "Network Competition: II. Price Discrimination." RAND Journal of Economics, RAND Journal of Economics, 29, no. 1 (1998): 38-56.

"Network Competition: I. Overview and Nondiscriminatory Pricing." RAND Journal of Economics, RAND Journal of Economics, 29, no. 1 (1998): 1-37.

Lee, Jongsu, Jeong-Dong Lee, Yeonbae Kim, and Yuri Park. "Estimating the Extent of Potential Competition in the Korean Mobile Telecommunications Market: Switching Costs and Number Portability." International Journal of Industrial Organization 24, no. 1 (2006): 107-24.

Majumdar, Sumit K., and S. Venkataraman. "Network Effects and the Adoption of New Technology: Evidence from the U. S. Telecommunications Industry." Strategic Management Journal 19, no. 11 (1998): 1045-62.

Park, Minjung. "The Economic Impact of Wireless Number Portability." The Journal of Industrial Economics 59, no. 4 (2011): 714-45.

"The Economic Impact of Wireless Number Portability." The Journal of Industrial Economics 59, no. 4 (2011): 714-45.

"Patriotic but Pricey; Telecoms in Canada." The Economist 408, no. 8852 (September 7, 2013): 38 .

Polo, Yolanda, and Juan Pablo Maicas. "Reducing the Level of Switching Costs in Mobile Communications." Telecommunications Policy 33, no. 9 (2009): 544-54.

Prezerakos, G. N., and S. E. Polykalas. "Maximizing the Adoption of Fixed Number Portability within the EU: An Empirical Analysis." Telecommunications Policy 31, no. 3 (2007): 179-96. 
Shi, Mengze, Jeongwen Chiang, and Byong-Duk Rhee. "Price Competition with Reduced Consumer Switching Costs: The Case of 'Wireless Number Portability' in the Cellular Phone Industry." Management Science, Management Science, 52, no. 1 (2006): 27-38.

Shin, Dong Hee. "A Study of Mobile Number Portability Effects in the United States." Telematics and Informatics 24, no. 1 (2007): 1-14.

Shin, Dong-Hee, and Won-Yong Kim. "Forecasting Customer Switching Intention in Mobile Service: An Exploratory Study of Predictive Factors in Mobile Number Portability." Technological Forecasting \& Social Change 75, no. 6 (2008): 854-74. doi:10.1016/j.techfore.2007.05.001.

Srinuan, Pratompong. "Evaluating the Swedish Mobile Communications Market: Switching Costs and Network Effects," 2010.

http://swepub.kb.se/bib/swepub:oai:services.scigloo.org:121366?tab2=abs\&language=en.

Swann, G. M. Peter, and Daniel Birke. "Network Effects and the Choice of Mobile Phone Operator.” Journal of Evolutionary Economics 16, no. 1/2 (2006): 65-84. 
Figure 4.2.1 Industry Growth with and without Network Effects

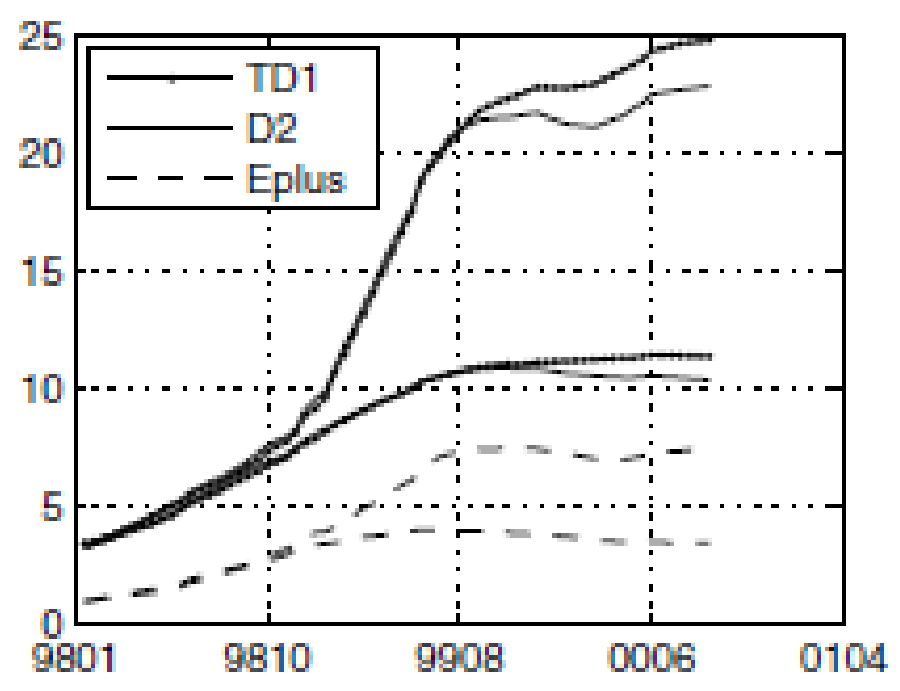

Note: TD1, D2 and Eplus are the tree main network operators which cover about $91 \%$ of the market.

Source: Doganoglu and Grzybowski (2007, p74). 
Figure 4.2.3 Development of On- and off-net call volumes

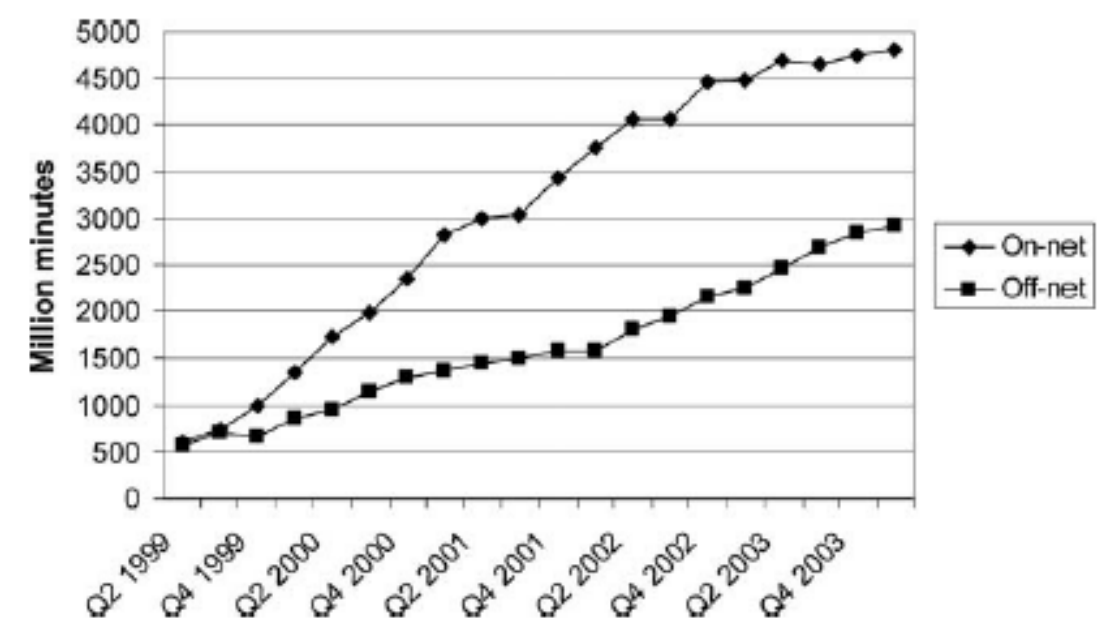

Source: Birke and Swann (2006, p73). 


\section{Figure 4.3 Direct Costs of WNP Using ONS or IN Technology}

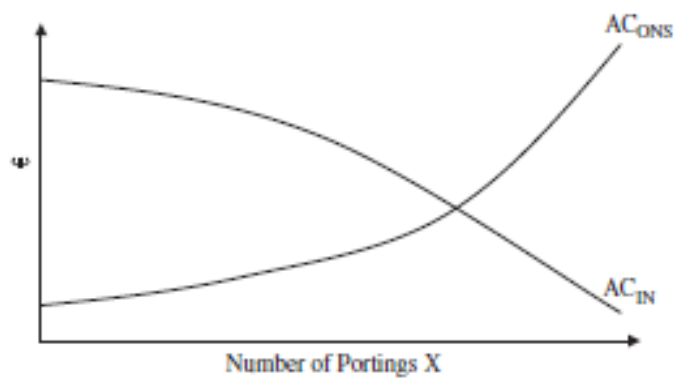

Note: Buehler et al. (2006) use different terminology so $\mathrm{AC}_{\mathrm{IN}}$ is what we have referred to as terminating-IN and $\mathrm{AC}_{\mathrm{ONS}}$ is what we have referred to as originating-IN.

Source: Bühler, Dewenter, and Haucap (2006, p390). 
Table 4.1.1 Evolution of WNP Implementation in the European Union

\begin{tabular}{|c|c|c|c|c|c|}
\hline \multirow[t]{2}{*}{ Country } & \multirow[t]{2}{*}{ MNP introduction } & \multicolumn{2}{|l|}{ Customer fee $(€)$} & \multicolumn{2}{|l|}{ Portability period (days) } \\
\hline & & When MNP introduced ${ }^{a}$ & 2009 & When MNP introduced ${ }^{a}$ & 2009 \\
\hline United Kingdom & January-99 & 0 & 0 & 30 & 2 \\
\hline Netherlands & April-99 & 9.5 & 0 & 60 & 3 \\
\hline Spain & December-00 & 0 & 0 & 5 & 5 \\
\hline Denmark & July-01 & 10 & 0 & 14 & \\
\hline Sweden & September-01 & 4 & 0 & 5 & 3 \\
\hline Portugal & January-02 & 40 & 0 & 20 & 3.7 \\
\hline Italy & April-02 & 10.02 & 0 & 15 & 5 \\
\hline Belgium & November-02 & 0 & 0 & 2 & 2 \\
\hline Germany & November-02 & 25.5 & 25.5 & 7 & 0 \\
\hline France & June-03 & 15 & 0 & 45 & 7 \\
\hline Ireland & July-03 & 0 & 0 & 0.08 & 0.08 \\
\hline Finland & July- 03 & 0 & 0 & 5 & 5 \\
\hline Lithuania & January-04 & 0 & 0 & 28 & 5 \\
\hline Greece & March-04 & 28.1 & 0 & 25 & 12 \\
\hline Hungary & May-04 & 30 & 0 & 10 & 6 \\
\hline Slovakia & May-04 & & 5.56 & & 5 \\
\hline Cyprus & July-04 & & 0 & & 4 \\
\hline Austria & October-04 & 19 & 19 & 3 & 3 \\
\hline Estonia & January-05 & & 0 & & 10 \\
\hline Luxembourg & February-05 & & 0 & & 4 \\
\hline Malta & Juyl-05 & & 0 & & 1 \\
\hline Latvia & December-05 & & 0 & & 2.5 \\
\hline Slovenia & December-05 & 10 & 5 & 7 & 3 \\
\hline Czech Republic & January-06 & & 0 & 14 & 3 \\
\hline Poland & February-06 & 15 & 0 & 8 & 1 \\
\hline Bulgaria & April-08 & & 2.56 & & 10 \\
\hline Romania & October-08 & & 0 & & 8.5 \\
\hline Average & & 12.00 & 2.13 & 15.9 & 4.3 \\
\hline Median & & 10 & 0 & 10 & 3.8 \\
\hline
\end{tabular}

Source: Asimakopoulos and Sánchez (2012, p189). 
Table 4.3.1 Ported Numbers in European Countries

\begin{tabular}{|c|c|c|c|c|}
\hline Country & Period & Ported numbers & $\begin{array}{l}\text { Avg. ported numbers } \\
\text { (monthly) }\end{array}$ & $\begin{array}{l}\text { Perentage of all } \\
\text { subscribers }\end{array}$ \\
\hline UK & $1 / 1999-8 / 2004$ & 3036863 & 44659.75 & 5.6 \\
\hline Spain & $12 / 2002-8 / 2004$ & 2091515 & 99595.95 & 5.5 \\
\hline Finland & $7 / 2003^{a}-8 / 2004$ & 993578 & 76429.07 & 20.8 \\
\hline Netherlands & $4 / 1999-8 / 2004$ & 925343 & 17459.30 & 6.9 \\
\hline Belgium & $10 / 2002-8 / 2004$ & 500408 & 21756.86 & 6.2 \\
\hline Sweden & $9 / 2001-8 / 2004$ & 486936 & 13526.00 & 5.6 \\
\hline Germany & $11 / 2002-8 / 2004$ & 349000 & 15863.63 & 0.6 \\
\hline Ireland & $7 / 2003^{a}-8 / 2004$ & 142414 & 10954.92 & 4.1 \\
\hline Lithuania & $1 / 2004-8 / 2004$ & 130000 & 16250.00 & na. \\
\hline France & $7 / 2003-8 / 2004$ & 100000 & 7142.85 & 0.2 \\
\hline
\end{tabular}

Source: Bühler, Stefan and Dewenter (2006, p394). 